\title{
Heat Transfer Modelling of Plate Heat Exchanger in Solar Heating System
}

\author{
Yan Jia*, Can Wang*, Zehui Chang, Wenxiong Li, Chi Zhang \\ Department of Energy and Power Engineering, Inner Mongolia University of Technology, Hohhot, China \\ Email: *2497331641@qq.com,421388331@qq.com
}

How to cite this paper: Jia, Y., Wang, C., Chang, Z.H., Li, W.X. and Zhang, C. (2017) Heat Transfer Modelling of Plate Heat Exchanger in Solar Heating System. Open Journal of Fluid Dynamics, 7, 426-447. https://doi.org/10.4236/ojfd.2017.73029

Received: July 25, 2017

Accepted: September 25, 2017

Published: September 28, 2017

Copyright $\odot 2017$ by authors and Scientific Research Publishing Inc. This work is licensed under the Creative Commons Attribution International License (CC BY 4.0).

http://creativecommons.org/licenses/by/4.0/

\begin{abstract}
Plate heat exchanger can obtain higher thermal performance because of its advantages in high heat transfer coefficient, small scale, and can realize pure counter current flow. It has been widely applied in HVAC industry. In this paper, the numerical research of plate heat exchanger in solar heating system has been proposed. Aimed at the type of herringbone corrugated plate which has better thermal performance and been widely used, the three dimensional model is established by Gambit software. Using FLUENT software for numerical calculation, by studying the effect of corrugated inclination angle, corrugated depth, corrugated spacing and inlet velocity of heat exchanger on internal temperature, pressure, velocity distributions of domains, the relationship between the above parameters and the Nusselt Number and the pressure drop was obtained by simulation data. Heat transfer coefficient and pressure drop correlations used to measure the overall performance of the heat exchanger. The result shows that the optimal structure parameters is corrugated angle $60^{\circ}$, corrugated depth $4 \mathrm{~mm}$ and corrugated spacing $16 \mathrm{~mm}$.
\end{abstract}

\section{Keywords}

Plate Heat Exchanger, Performance, Pressure Drop, CFD

\section{Introduction}

The availability of resources and energy is a serious problem of the whole world. Because of the environment, resources and energy crisis in recent years, the requirement of saving energy and reducing consumption is increasingly high, and using efficient heat exchange equipment to reduce the energy consumption has become the focus of modern industry attention and study. Compared with the traditional shell and tube heat exchanger, the development of plate heat ex- 
changer has the obvious advantage [1] [2] [3].

Plate heat exchanger is a kind of efficient and compact heat exchange equipment and its application involves almost all industrial fields. In recent years, brazing type plate heat exchanger has been known by people widely by its superiority of good compactness, light weight, good heat transfer performance and low initial cost. Therefore, it is very necessary to find an effective and feasible method for the study of flow and heat transfer between heat exchanger plates. It is generally recognized that herringbone corrugated plate have higher heat transfer efficiency, big resistance and bearing capacity, because the complex change in plate flow channel section is easy to induce turbulence and the fluid flow consumes more energy in this kind of variable flow [4] [5] [6] [7].

Each plate shall be four angle hole, there are two angle hole provide flow channel on the each side of the plate. When assembling plate, angle hole is arranged into bypass duct of two fluids in proper order. In a group of channel, fluid flow between the two plate after entering angle hole and outflow from the other hole. Each kind of fluid has a single port because of sheet gasket alternant of angle hole. The most common material of plate heat exchanger is stainless steel and titanium, sometimes using nickel alloy steel [8] [9] [10].

How to use the remaining energy reasonably and improve energy utilization has become a research direction for experts and scholars from all over the world. Authors of [11] studied evaporating heat transfer characteristics and pressure drop of $\mathrm{R}-404 \mathrm{a}$ in brazing type plate heat exchanger and using geometry on the Nusselt Number and friction factor for correction. In the paper [12], the difference of pressure drop from the port to the channel process of steam in plate heat exchanger has been studied. In the paper [13], simulations of stirred yoghurt processing in a plate heat exchanger were performed using computational fluid dynamics (CFD) calculations and the results compared with experimental data. After analysis of the velocity field and fanning friction factors, relations are proposed for the present heat exchanger between fanning factors and Reynolds Number and between mean shear rate and mean velocity of yoghurt. The paper [14] explored the potential of using a general purpose CFD code to compute the characteristics of the flow field, and of the heat transfer augmentation in conduits with corrugated walls, encountered in PHE. The code is validated by comparing the numerical results with experimental data on pressure drop and overall temperature differences. It is shown that the CFD code is an effective and reliable tool for studying the effect of various geometrical configurations on the optimum design of a PHE. The aim of paper [15] is to compare a well-established and validated CFD code both with results obtained from an experimental PHE model. The results show that CFD simulation can predict heat transfer rate and fluid flow behavior in arrange of Re Numbers, with discrepancies up to $1 \%$ and $6 \%$ in terms of outlet temperature and pressure drop respectively. In paper [16], the thermal and hydraulic characteristics of corrugated fluid channels of compact brazed heat exchangers (BPHE) are investigated by computational fluid dynamics (CFD) software ANSYS CFX 14.0. The influence of geometry parameters of the cor- 
rugated pattern on the BPHE performance is investigated on small fluid section geometries. The influence of various types of wall heat transfer boundary conditions on the simulation results is also studied. The simulations of the entire fluid channel under predict heat transfer and pressure drop by $20 \%-30 \%$ and $10 \%-35 \%$, respectively. The article [17] presents a detailed analysis of the thermo hydraulic transfers for single-phase flow in brazed plate heat exchangers (BPHE) using numerical simulations. Whether for simulations or experiments, there is a significant change in the hydraulic behavior for $\mathrm{Re} \approx 200$, which may suppose a change of the flow structure into the BPHE. The study reveals two categories of PHE hydraulic behavior depending on the chevron angle with a limit around $60^{\circ}$ for the change of the PHE behavior.

In this paper, numerical simulation is conducted for the most widely used herringbone corrugated plate heat exchanger. The temperature field and pressure field of the fluid in the channel between the plates were simulated and the main factors influencing the heat transfer and flow were analyzed. At the same time, by analyzing the performance of the plate heat exchanger and analyzing the heat transfer performance and resistance characteristics, the relationship between plate heat exchanger performance and geometrical parameters of corrugated plate are researched to provide the theoretical basis for the optimization and development of the plate heat exchanger plate.

\section{Method}

\subsection{Numerical Method}

In the process of numerical simulation, we must first establish the mathematical model which reflects the nature of the problem, that is, reflect the differential equation and the definite condition between the various problems, and then find the high efficiency and high precision calculation method.

Combined with the characteristics of flow and heat transfer in the actual plate heat exchanger, the mathematical model based on the numerical simulation is mainly used as follows:

1) The working medium is incompressible Newtonian fluid;

2) Gravity and floating capacity due to density differences are ignored;

3) Due to the lower flow velocity of the fluid in the heat exchanger, ignore the thermal effect of the viscous dissipation when the fluid flows;

4) Assuming that the fluid inlet speed is known, the outlet pressure is constant. The inlet pressure and outlet speed are free boundary conditions.

The control equations for the fluid motion and heat transfer in the calculation region are as follows:

Conti Nuity equation:

$$
\frac{\partial u_{i}}{\partial x_{i}}=0
$$

Mass conservation equation: 


$$
\frac{\partial u}{\partial x}+\frac{\partial v}{\partial y}+\frac{\partial w}{\partial z}=0
$$

where $u, v, w$ is the component of flow velocity.

The momentum conservation equation in the $i$-direction Cartesian coordinate system:

$$
u \frac{\partial U i}{\partial x}+v \frac{\partial U i}{\partial y}+w \frac{\partial U i}{\partial z}=-\frac{1}{\rho} \frac{\partial p}{\partial x^{2}}+v\left(\frac{\partial^{2} U i}{\partial x^{2}}+\frac{\partial^{2} U i}{\partial y^{2}}+\frac{\partial^{2} U i}{\partial z^{2}}\right)
$$

where $\rho$ is the fluid density, $p$ is the pressure, $v$ is the kinematic viscosity, and $U i$ is the velocity component in the $i$ direction.

Energy conservation equation:

$$
u \frac{\partial t}{\partial x}+v \frac{\partial t}{\partial y}+w \frac{\partial t}{\partial z}=a \frac{\partial^{2} t}{\partial x^{2}}+\frac{\partial^{2} t}{\partial y^{2}}+\frac{\partial^{2} t}{\partial z^{2}}
$$

where $a$ is the thermal diffusion coefficient.

There are two main categories of turbulence models: Reynolds stress model and vortex model. In the vortex model, the Reynolds stress term is not directly processed, but the turbulence viscosity is introduced, and then the turbulence stress is expressed as a function of the turbulence viscosity, which reduces the difficulty of solving. The vortex model includes zero-equation model, one-equation model, and two-equation model. The standard $\mathrm{k}-\varepsilon$ model is a typical two-equation model, which is formed by introducing the turbulence dissipation rate $\varepsilon$ on the basis of the k-equation, which is the most widely used turbulence model. In this paper, the RNG model in the $\mathrm{k}-\mathcal{E}$ turbulence model is used as the renormalization group model, can deal better with high strain rate and the flow with larger flow line bending degree, due to correct the turbulence viscosity, take into account the rotational flow in the average flow, add an item to $\mathcal{E}$, reflect the mainstream time-dependent change rate $E_{i j}$. Because the RNG model is only for the turbulence with full development, so wall function method is adopted for low Reynolds Number movement near the wall, the dense and a large Number of grid layout on the wall saves memory and time, which is widely used in engineering turbulence calculation.

\subsection{Meshing and Boundary Conditions}

The object of this study is EATB55 brazing plate heat exchanger, the size of which is $539 \mathrm{~mm}$ long, width of which is $123 \mathrm{~mm}$, and the plate thickness of which is $2.34 \mathrm{~mm}$. The model created using gambit is shown in Figure 1. As the corrugated structure of the plate heat exchanger is complex, and the arrangement of which is dense, the unstructured tetrahedral mesh is adopted to divide the grid, and the grid size should be $1 \mathrm{~mm}$, which is appropriate, and the total Number of grids is about 800,000 , making the computer memory reasonable.

In order to explore the main factors that affect the performance of the plate heat exchanger, the corrugated angel, the corrugated depth and the corrugated spacing are defined as shown in Figure 2. The corrugated angle is $30^{\circ}$ to $70^{\circ}$, the 


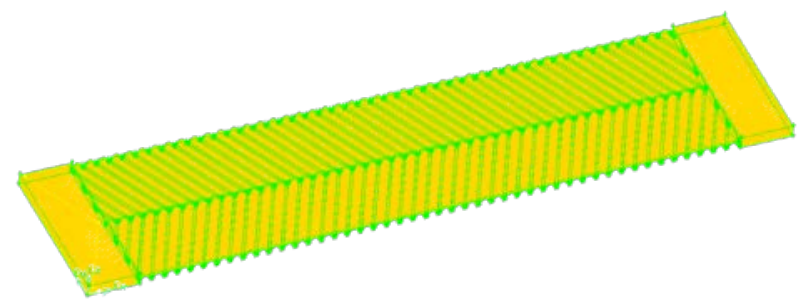

Figure 1. The 3D model of corrugated plate.

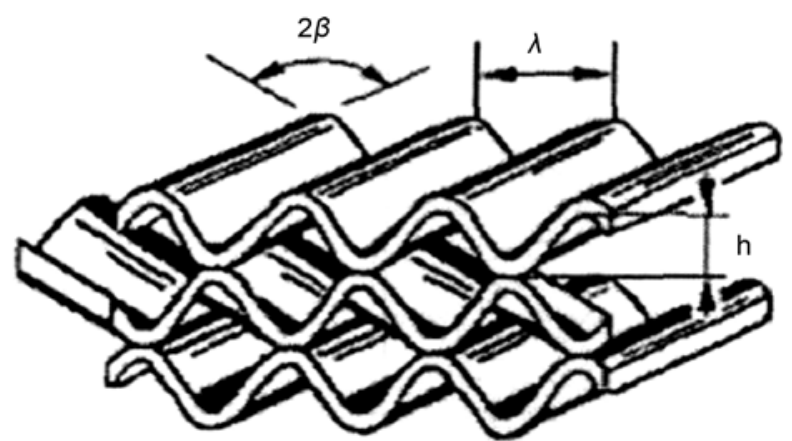

Figure 2. The performance of the PHE.

ripple depth is $3 \mathrm{~mm}$ to $6 \mathrm{~mm}$, and the ripple pitch is $10 \mathrm{~mm}$ to $20 \mathrm{~mm}$.

The geometrical parameters of the plate for the stimulation of the single corrugated plate and the selection of the velocity of the plate are shown in Table 1.

Boundary condition setting:

1) Fluid inlet adopts speed inlet boundary conditions: Assuming inlet speed is $0.6 \mathrm{~m} / \mathrm{s}$ and inlet temperature is set to $300 \mathrm{~K}$;

2) The outlet of the fluid adopts pressure outlet boundary conditions, set the outlet pressure as 101,325 $\mathrm{Pa}$;

3) The upper and lower wall is set to constant wall, temperature $340 \mathrm{~K}$;

4) The remaining walls are non-slip adiabatic walls, and the fluid medium is water.

\section{Result and Discussion}

\subsection{Numerical Results}

The pressure distribution at different angle, when the spacing $\lambda=16 \mathrm{~mm}$, depth $h=4 \mathrm{~mm}, v=0.6 \mathrm{~m} / \mathrm{s}$ is shown in Figure 3 .

The temperature distribution at different angles is shown in Figure 4.

The velocity distribution at different angles is shown in Figure 5.

The local vector velocity at different angles is shown in Figure 6.

The corrugated angle is smaller, the local vector velocity around the corner is higher, the pressure is higher, the temperature is higher as well, the highest temperature appears at the corner. When $\beta=30^{\circ}$ the details of local vector velocity is shown in Figure 7(a) and the temperature distribution is shown in Figure 7(b). Due to the plate heat exchanger has a wide range of bearing temperature, 
Table 1. Calculate parameters.

\begin{tabular}{ccccc}
\hline Angle $\beta^{\circ}$ & Depth $h \mathrm{~mm}$ & Spacing $\lambda \mathrm{mm}$ & Fluid inlet velocity $\mathrm{m} / \mathrm{s}$ & Number of grids \\
\hline 30 & 4 & 16 & 0.6 & 849,390 \\
45 & 4 & 16 & 0.6 & 846,700 \\
60 & 4 & 16 & 0.6 & 837,523 \\
70 & 4 & 16 & 0.6 & 883,559 \\
\hline Angle $\beta^{\circ}$ & Depth $h \mathrm{~mm}$ & Spacing $\lambda \mathrm{mm}$ & Fluid inlet velocity $\mathrm{m} / \mathrm{s}$ & 817,623 \\
60 & 4 & 10 & 0.6 & 790,833 \\
60 & 4 & 12 & 0.6 & 837,523 \\
60 & 4 & 16 & 0.6 & 795,245 \\
60 & 4 & 20 & 0.6 & Number of grids \\
\hline Angle $\beta^{\circ}$ & Depth $h \mathrm{~mm}$ & Spacing $\lambda$ mm & Fluid inlet velocity $\mathrm{m} / \mathrm{s}$ & 713,123 \\
60 & 3 & 16 & 0.6 & 837,523 \\
60 & 4 & 16 & 0.6 & 781,908 \\
60 & 5 & 16 & 0.6 & 786,612 \\
\hline
\end{tabular}
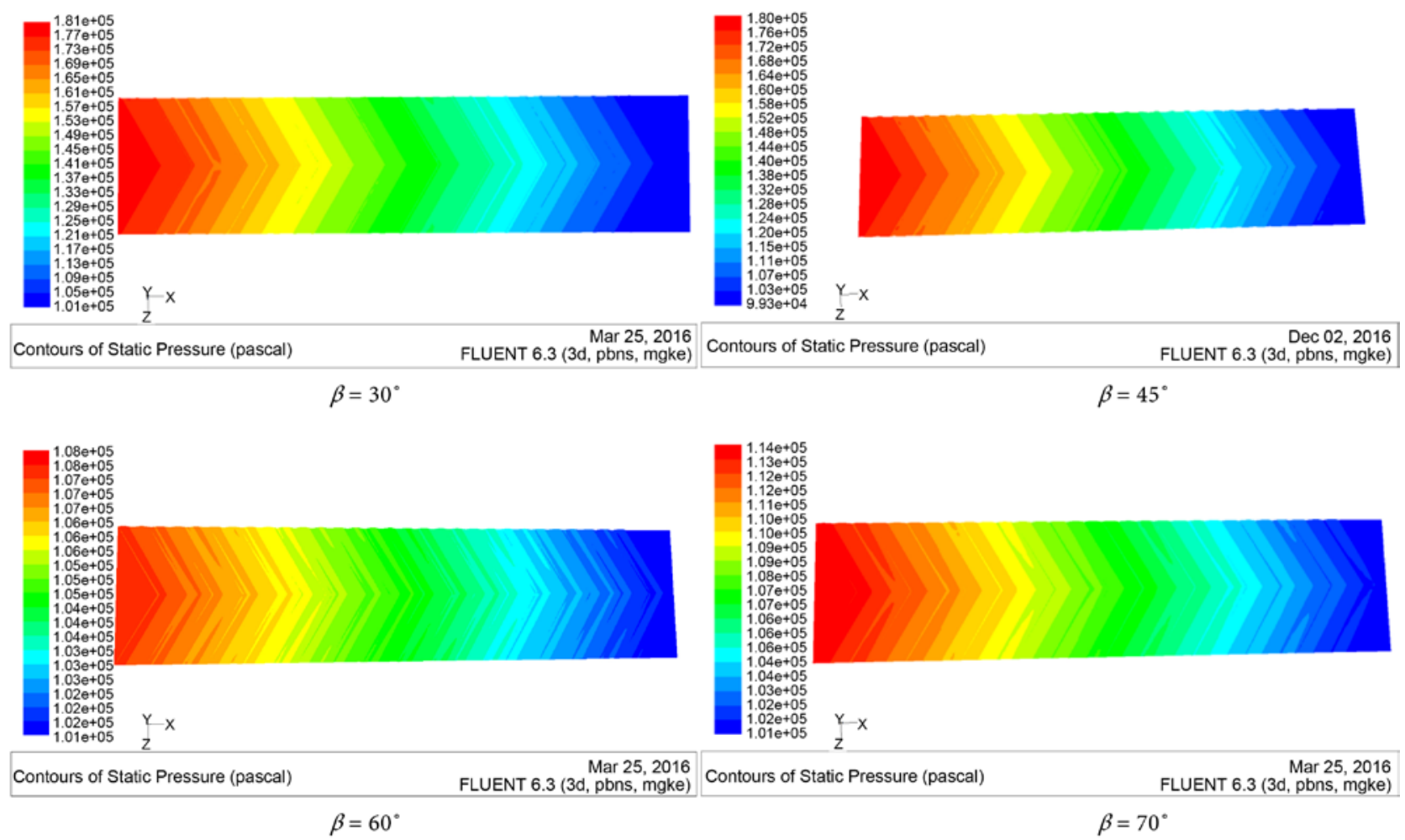

Figure 3. Pressure distribution at different angle.

and the whole plate velocity distribution uniform, the plate will not cause damage.

When angle $\beta=60^{\circ}$, depth $h=4 \mathrm{~mm}, V=0.6 \mathrm{~m} / \mathrm{s}$, the pressure distribution at different spacing is shown in Figure 8. 

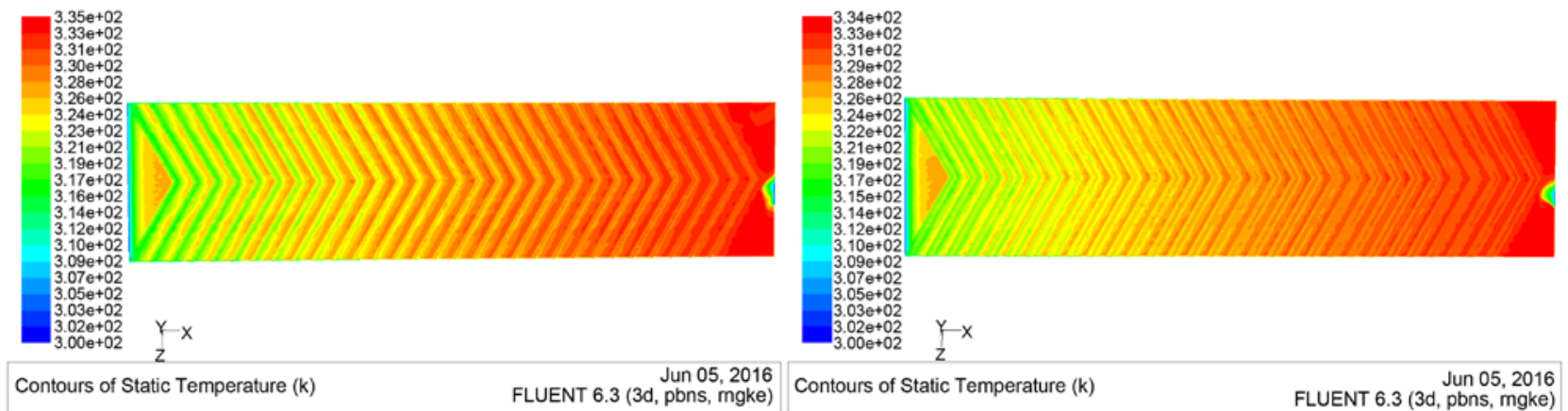

$$
\beta=30^{\circ}
$$

Contours of Static Temperature (k) FLUENT 6.3 (3d, pbns, mgke)

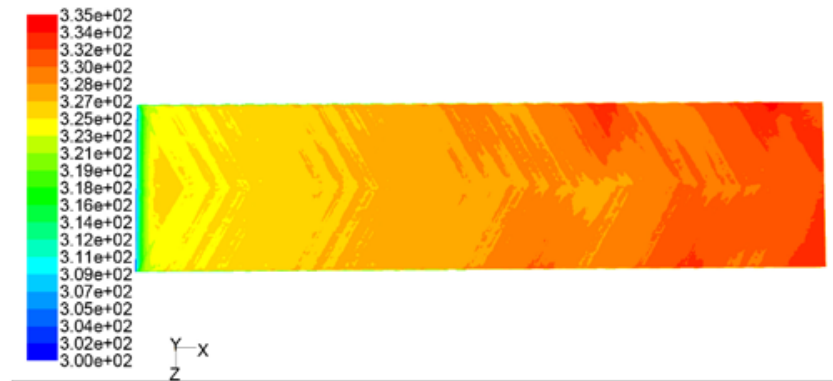

Contours of Static Temperature $(k)$ FLUENT 6.3 (3d, pbns, mgke)

$$
\beta=60^{\circ}
$$

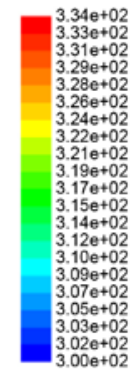

$\beta=45^{\circ}$

Contours of Static Temperature $(\mathrm{k})$

Mar 25, 2016

$\beta=70^{\circ}$

Figure 4. Temperature distribution at different angles.
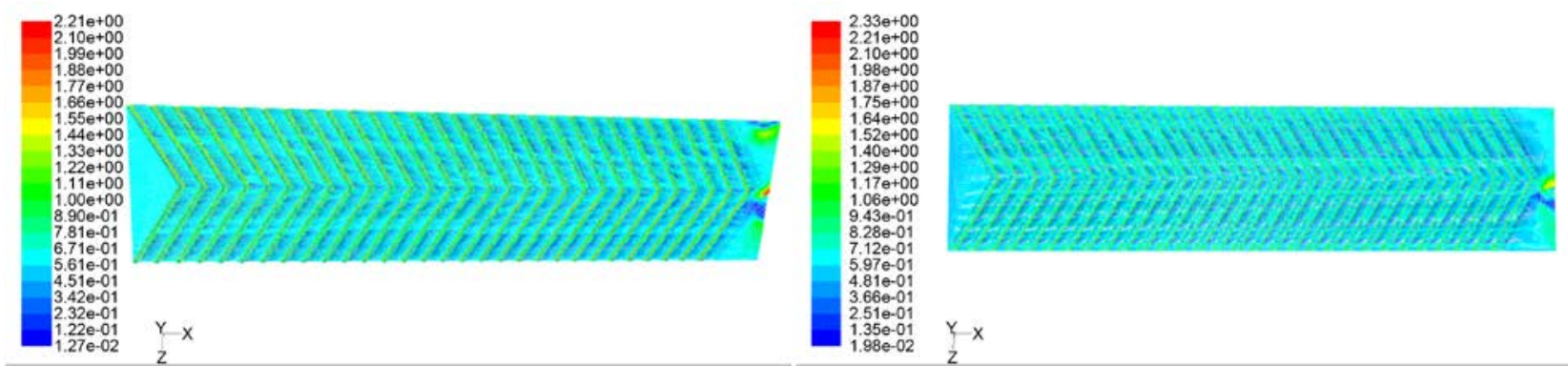

\begin{tabular}{|c|c|c|c|}
\hline Velocity Vectors Colored By Velocity Magnitude $(\mathrm{m} / \mathrm{s})$ & $\begin{array}{r}\text { Mar 25, } 2016 \\
\text { FLUENT } 6.3 \text { (3d, pbns, mgke) }\end{array}$ & Velocity Vectors Colored By Velocity Magnitude $(\mathrm{m} / \mathrm{s})$ & $\begin{array}{r}\text { Dec 04, } 2016 \\
\text { FLUENT 6.3 (3d, pbns, mgke) }\end{array}$ \\
\hline
\end{tabular}

Yx
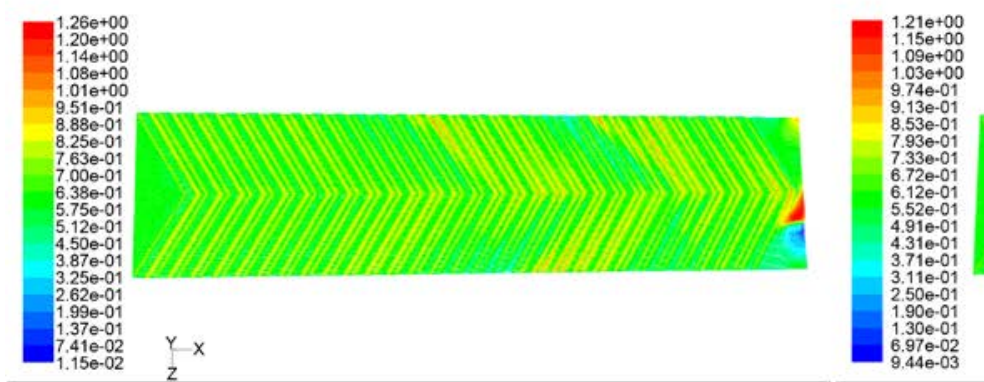

$\beta=45^{\circ}$

Velocity Vectors Colored By Velocity Magnitude (m/s) Far 25, 2016

$$
\beta=60^{\circ}
$$

r $x$ FLUENT 6.3 (3d, pbns, mgke) Velocity Vectors Colored By Velocity Magnitude $(\mathrm{m} / \mathrm{s})$ $\beta=70^{\circ}$

Figure 5. Velocity distribution at different angles.

The temperature distribution at different spacing is shown in Figure 9. 

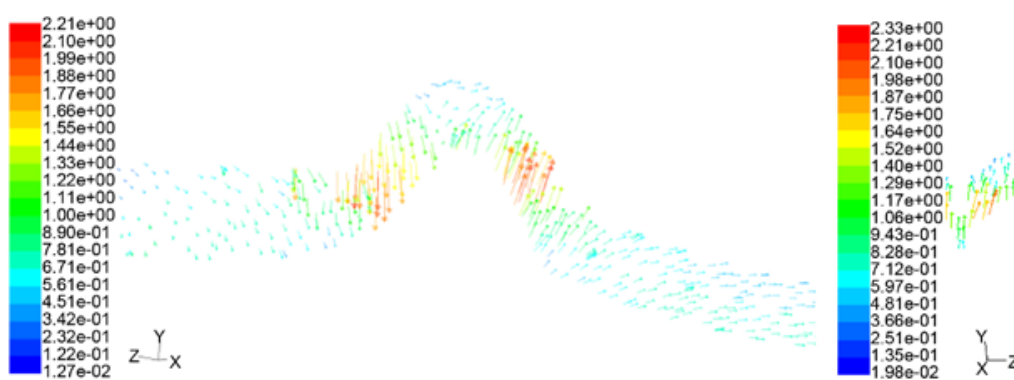

\begin{tabular}{|c|c|c|c|}
\hline Velocity Vectors Colored By Velocity Magnitude (m/s) & $\begin{array}{r}\text { Mar 25, } 2016 \\
\text { FLUENT } 6.3 \text { (3d, pbns, mgke) }\end{array}$ & Velocity Vectors Colored By Velocity Magnitude (m/s) & $\begin{array}{r}\text { Jun 05, } 2016 \\
\text { FLUENT } 6.3 \text { (3d, pbns, mgke) }\end{array}$ \\
\hline
\end{tabular}
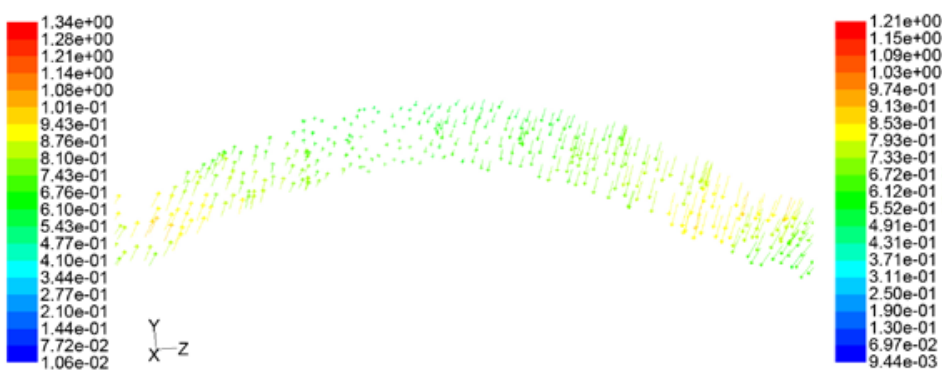

$x$

Velocity Vectors Colored By Velocity Magnitude (m/s) FLUENT 6.3 (3d, pbns, mgke)

$\begin{array}{rr}\text { Velocity Vectors Colored By Velocity Magnitude (m/s) } & \text { Mar 25, } 2016 \\ \text { FLUENT 6.3 (3d, pbns, mgke) }\end{array}$ $\beta=60^{\circ}$ $\beta=70^{\circ}$

Figure 6. The local vector velocity at different angles.

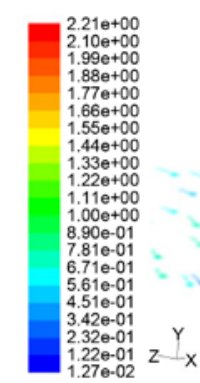

Velocity Vectors Colored By Velocity Magnitude $(\mathrm{m} / \mathrm{s})$

(a)

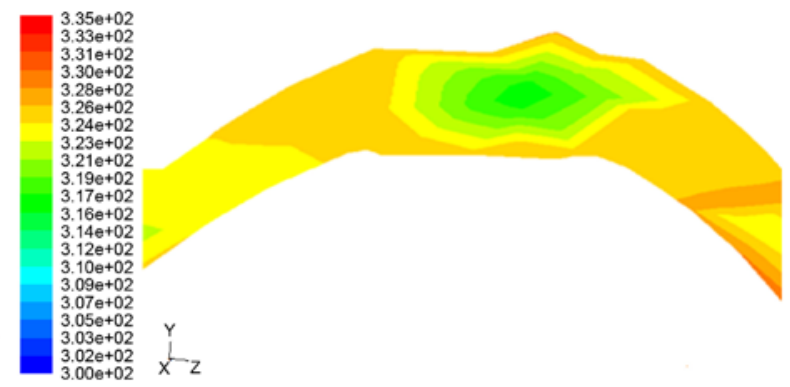

Contours of Static Temperature (k)
FLUENT 6.3 (3d, Jul 14, 2016 pbns, mike)

(b)

Figure 7. The details of local vector velocity and temperature distribution when $\beta=30^{\circ}$ : (a) Local vector velocity; (b) Temperature distribution.
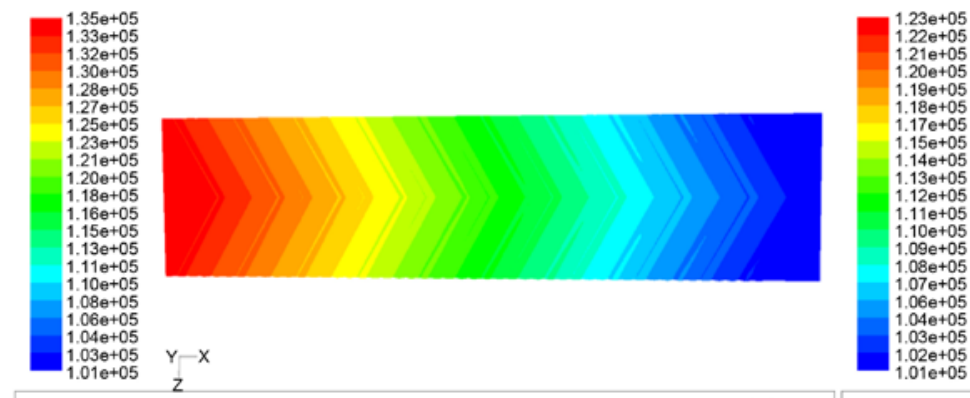

Contours of Static Pressure (pascal)

Mar 26, 2016

Contours of Static Pressure (pascal)

$Y \rightarrow X$

$$
\lambda=10 \mathrm{~mm}
$$

$$
\lambda=12 \mathrm{~mm}
$$




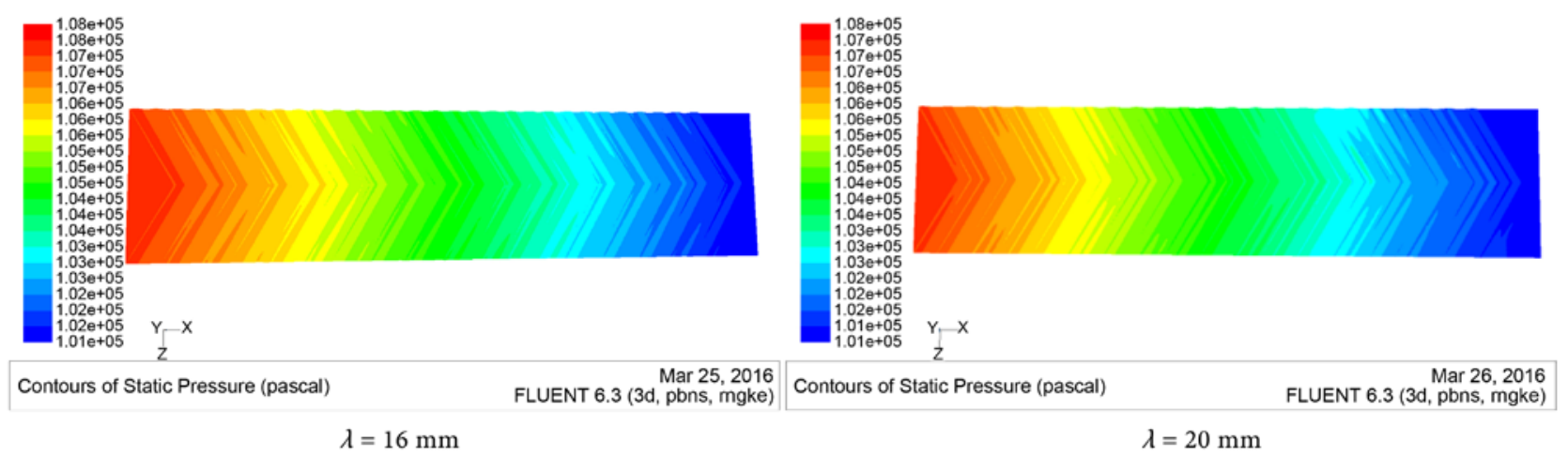

Figure 8. Pressure distribution at different spacing.
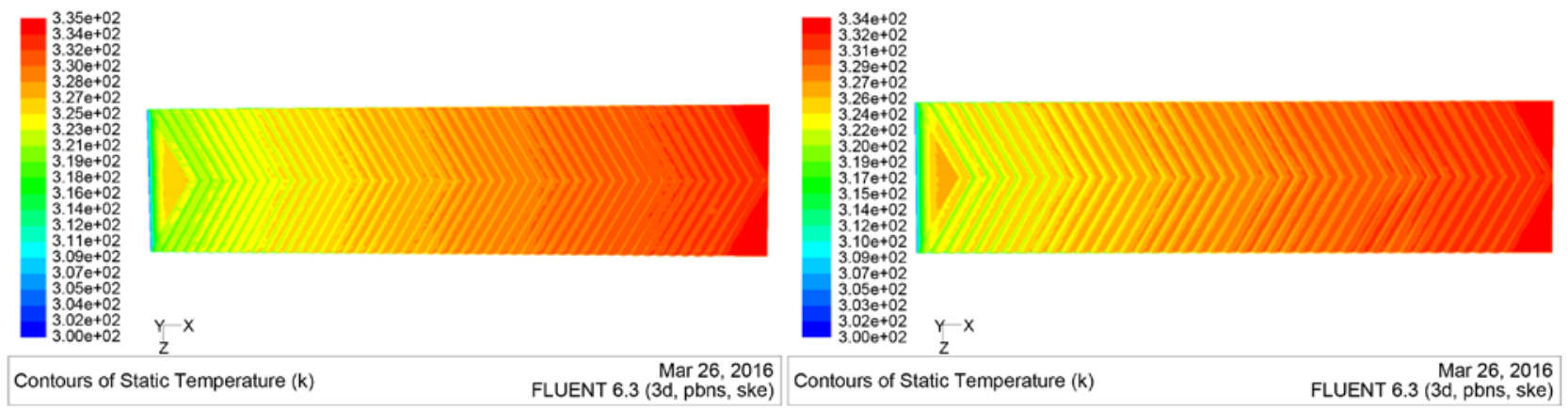

$\lambda=10 \mathrm{~mm}$

$\lambda=12 \mathrm{~mm}$

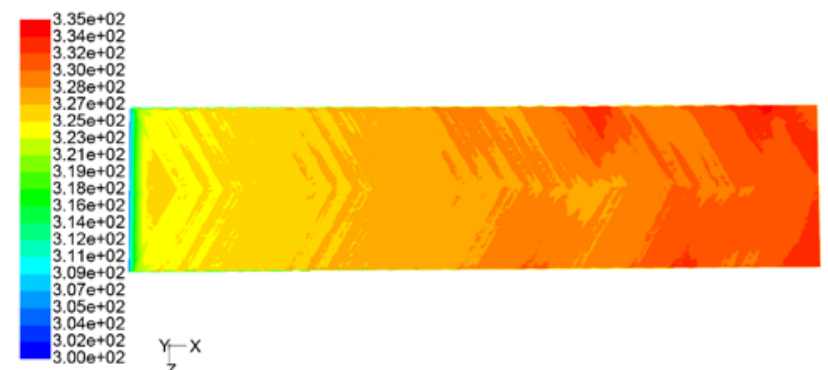

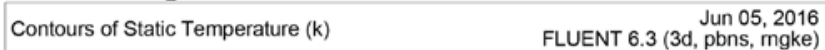

$\lambda=16 \mathrm{~mm}$

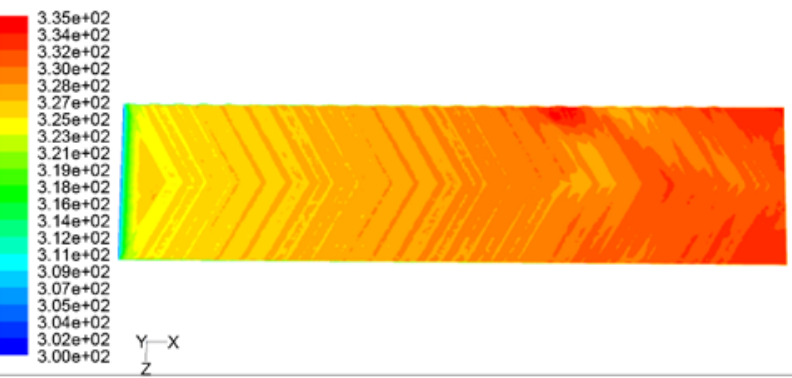

Contours of Static Temperature (k) FLUENT 6.3 (3d, pbns, mgke)

$\lambda=20 \mathrm{~mm}$

Figure 9. Temperature distribution at different spacing.

The velocity distribution at different spacing is shown in Figure 10.

The local vector velocity at different spacing is shown in Figure 11.

When angle $\beta=60^{\circ}$, spacing $\lambda=16 \mathrm{~mm}, v=0.6 \mathrm{~m} / \mathrm{s}$, pressure distribution at different depths is shown in Figure 12.

The temperature distribution at different depths is shown in Figure 13.

The velocity distribution at different depths is shown in Figure 14.

The local vector velocity at different depths is shown in Figure 15.

When angle $\beta=60^{\circ}$, spacing $\lambda=16 \mathrm{~mm}, h=4 \mathrm{~mm}$, the pressure distribution at different inlet velocity is shown in Figure 16.

The temperature distribution at different inlet velocity is shown in Figure 17.

The velocity distribution at different inlet velocity is shown in Figure 18. 

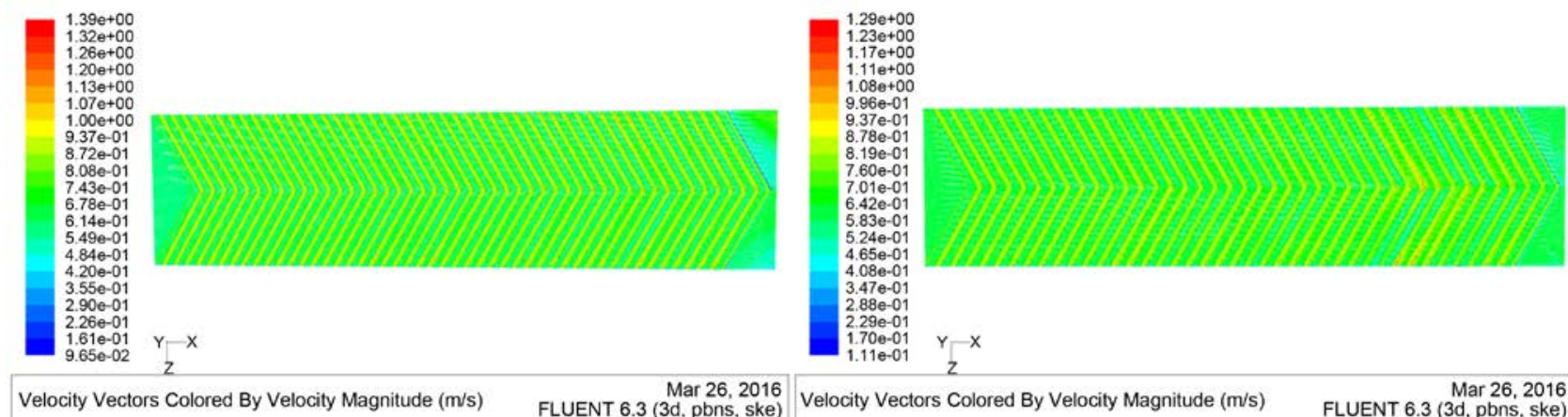

$$
\lambda=10 \mathrm{~mm}
$$

Velocity Vectors Colored By Velocity Magnitude (m/s) 26, 2016
FLUENT 6.3 (3d, pbns, ske)

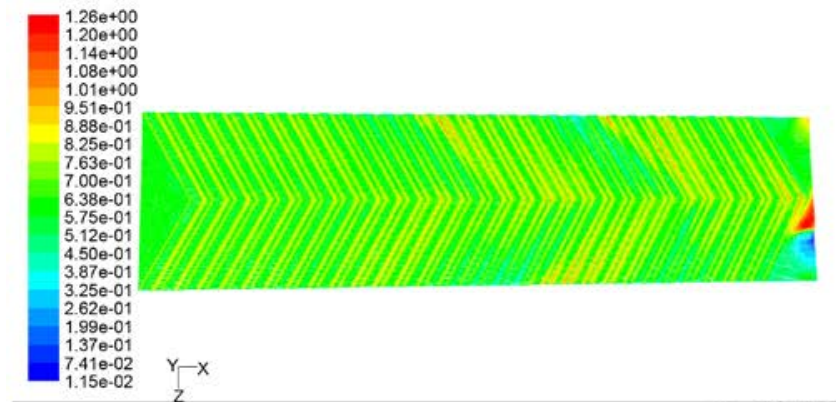

Velocity Vectors Colored By Velocity Magnitude (m/s) rLUENT 6.3 (3d, pbns, mgke)

$$
\lambda=16 \mathrm{~mm}
$$

$$
\lambda=12 \mathrm{~mm}
$$

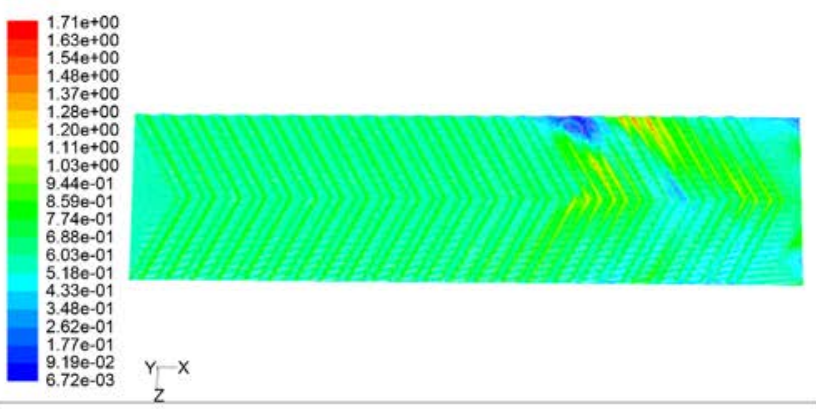
$\begin{array}{rr}\text { Velocity Vectors Colored By Velocity Magnitude (m/s) } & \text { Mar 26, } 2016 \\ \text { FLUENT } 6.3 \text { (3d, pbns, mgke) }\end{array}$

Figure 10. Velocity distribution at different spacing.
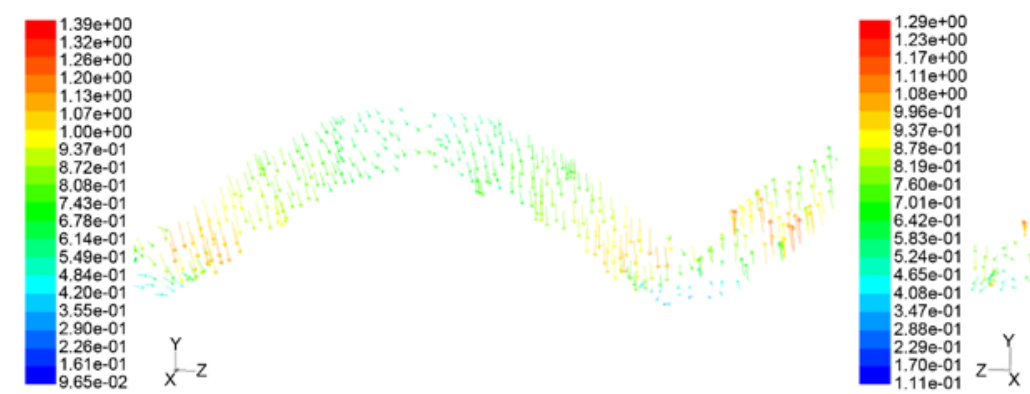

$\begin{array}{lr}\text { Velocity Vectors Colored By Velocity Magnitude (m/s) } & \text { Mar 26, } 2016 \\ \text { FLUENT 6.3 (3d, pbns, ske) }\end{array}$

Velocity Vectors Colored By Velocity Magnitude $(\mathrm{m} / \mathrm{s})$ Mar 26, 2016 $\lambda=10 \mathrm{~mm}$

$$
\lambda=12 \mathrm{~mm}
$$
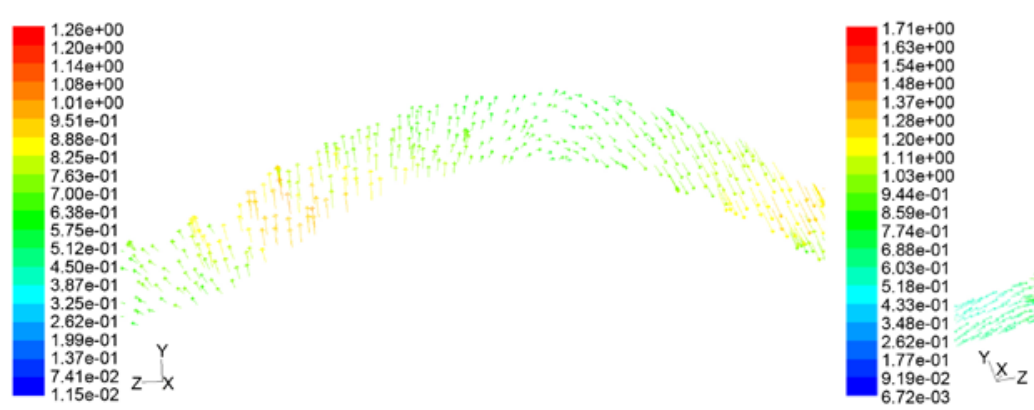
Velocity Vectors Colored By Velocity Magnitude (m/s) Mar 25, 2016

Velocity Vectors Colored By Velocity Magnitude $(\mathrm{m} / \mathrm{s})$

Mar 26, 2016

$$
\lambda=16 \mathrm{~mm}
$$$$
\lambda=20 \mathrm{~mm}
$$

Figure 11. Local vector velocity at different spacing. 


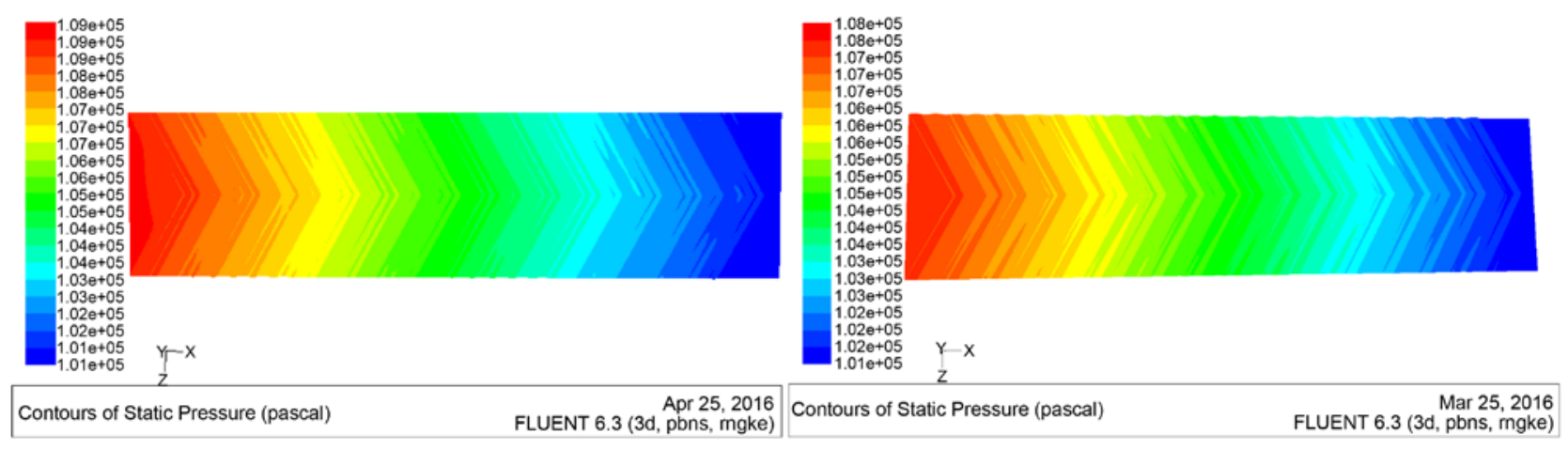

$$
h=3 \mathrm{~mm}
$$

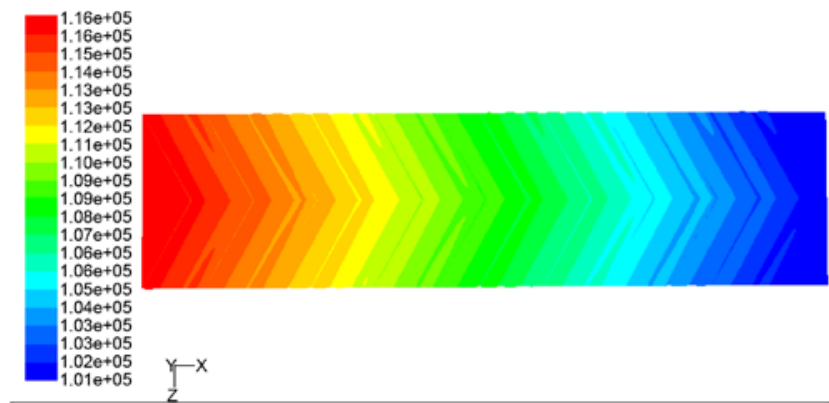

\begin{tabular}{|c|c|c|c|}
\hline Contours of Static Pressure (pascal) & $\begin{array}{r}\text { Apr 25, } 2016 \\
\text { FLUENT 6.3 (3d, pbns, ske) }\end{array}$ & Contours of Static Pressure (pascal) & $\begin{array}{r}\text { Apr 25, } 2016 \\
\text { FLUENT 6.3 (3d, pbns, mgke) }\end{array}$ \\
\hline
\end{tabular}

Figure 12. Pressure distribution at different depths.

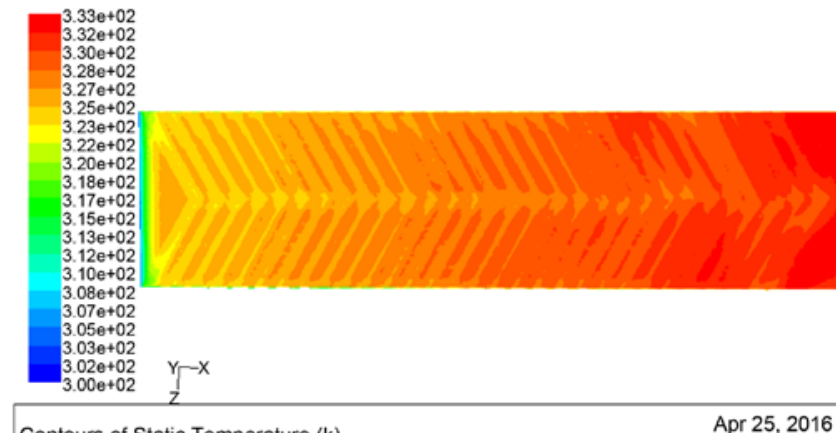

Contours of Static Temperature (k) $\quad$ FLUENT 6.3 (3d, pbrs, mgke) $h=3 \mathrm{~mm}$

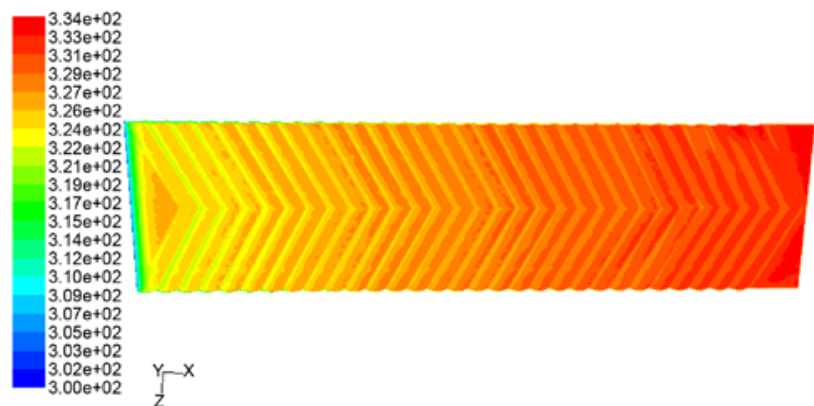

Contours of Static Temperature (k) Apr 25, 2016 $h=5 \mathrm{~mm}$

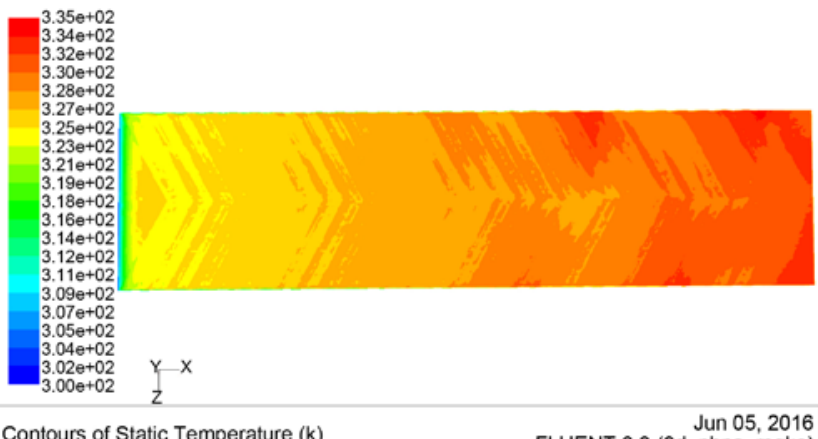

Contours of Static Temperature (k) FLUENT 6.3 (3d, pbns, mgke)

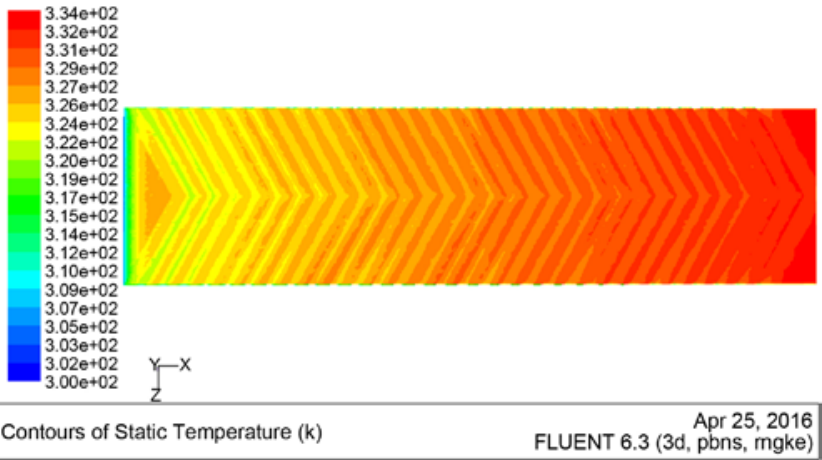

$h=6 \mathrm{~mm}$

Figure 13. Temperature distribution at different depths. 

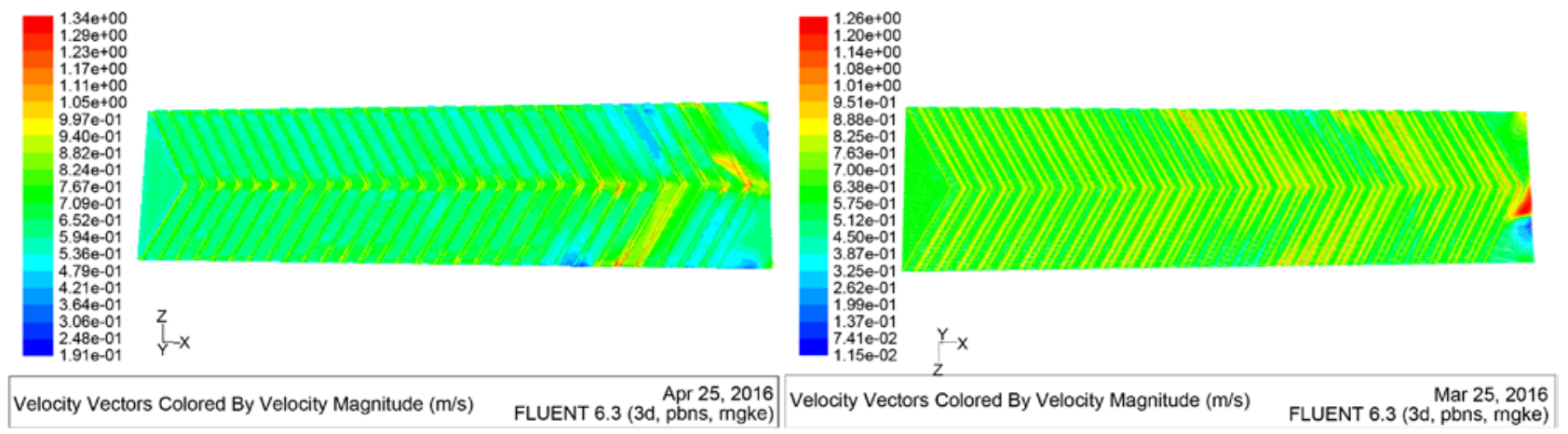

$$
h=3 \mathrm{~mm}
$$

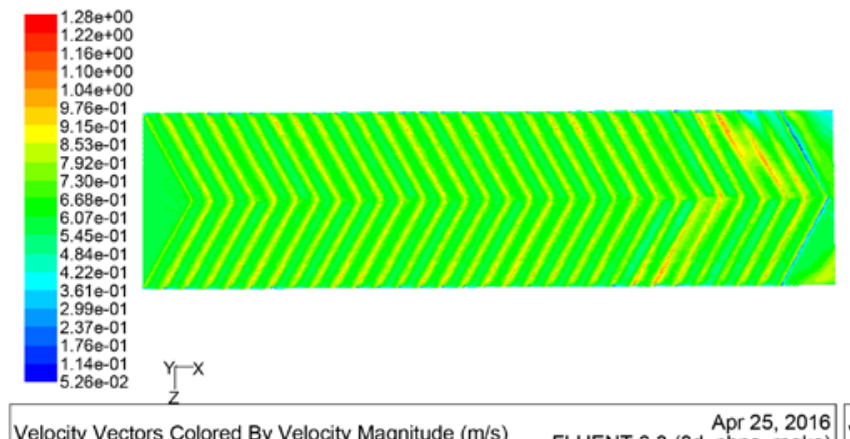

\begin{tabular}{|c|c|c|c|}
\hline Velocity Vectors Colored By Velocity Magnitude (m/s) & $\begin{array}{r}\text { Apr 25, } 2016 \\
\text { FLUENT } 6.3 \text { (3d, pbns, mgke) }\end{array}$ & Velocity Vectors Colored By Velocity Magnitude $(\mathrm{m} / \mathrm{s})$ & $\begin{array}{l}\text { Apr 25, } 2016 \\
\text { FLUENT } 6.3 \text { (3d, pbns, mgke) }\end{array}$ \\
\hline
\end{tabular}

Figure 14. Speed distribution at different depths.
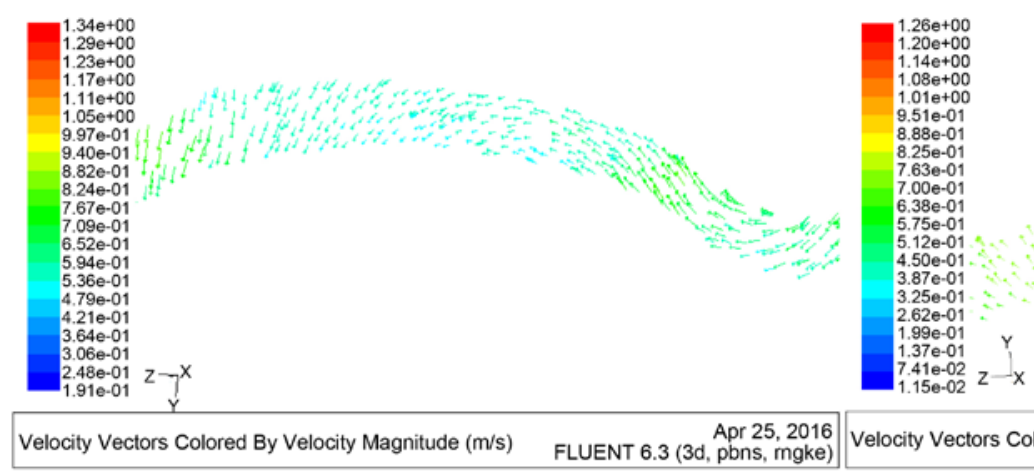

$$
h=3 \mathrm{~mm}
$$

\begin{tabular}{rr} 
Velocity Vectors Colored By Velocity Magnitude (m/s) & Mar 25, 2016 \\
\hline
\end{tabular}
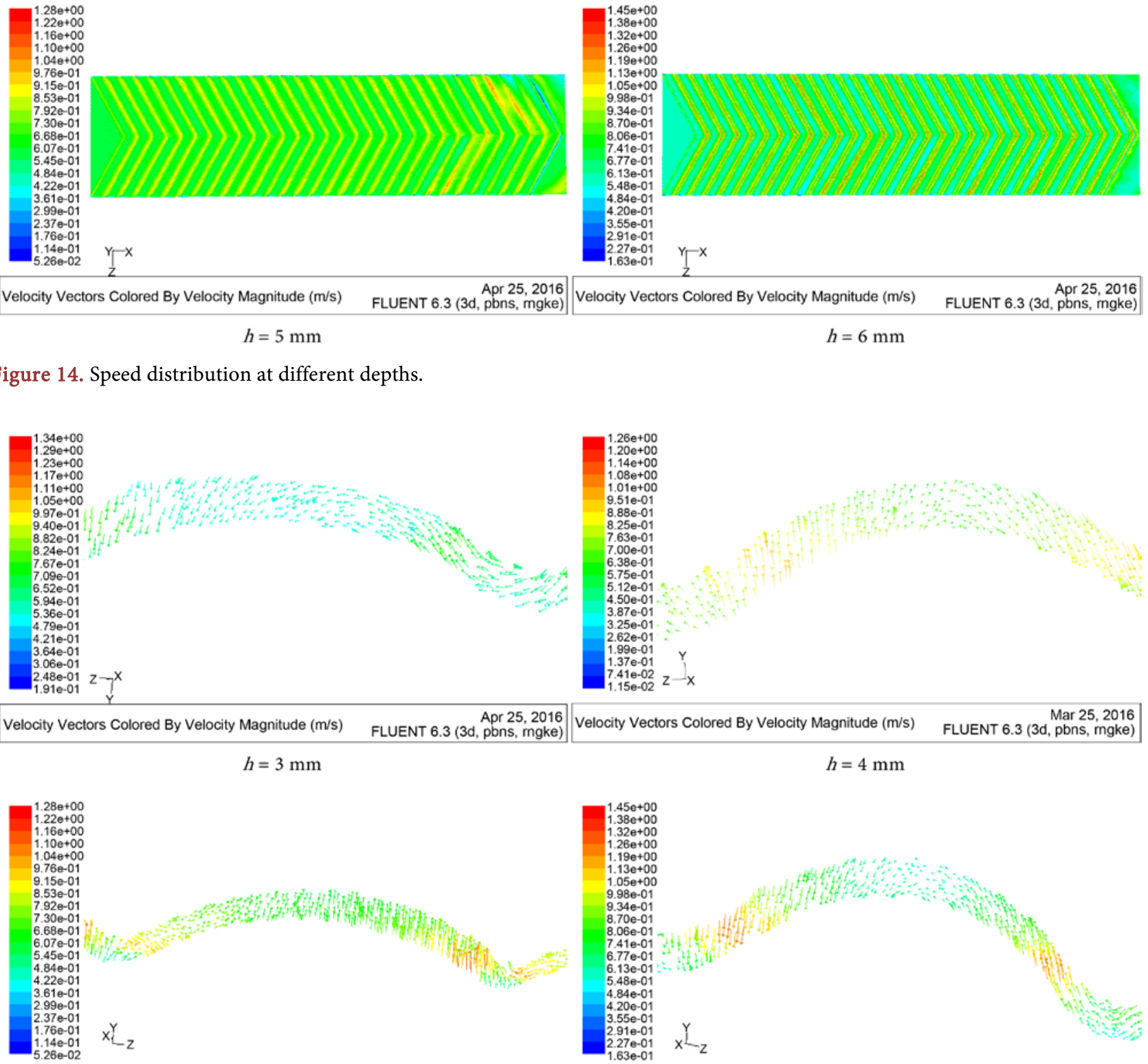

$$
h=4 \mathrm{~mm}
$$



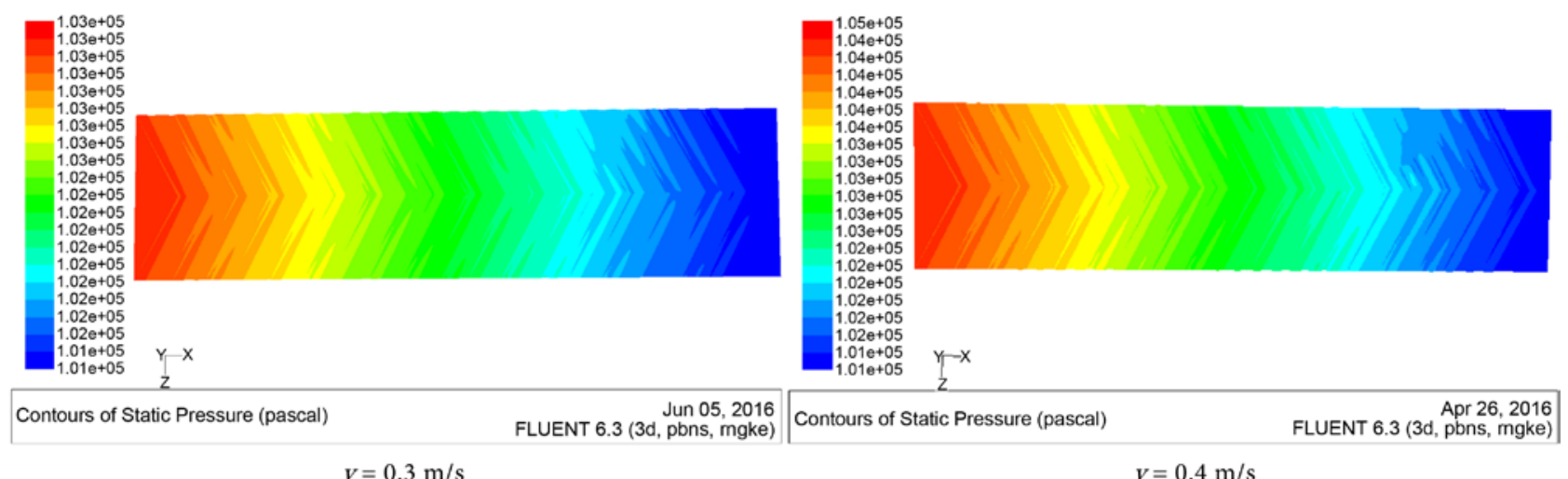

$V=0.3 \mathrm{~m} / \mathrm{s}$
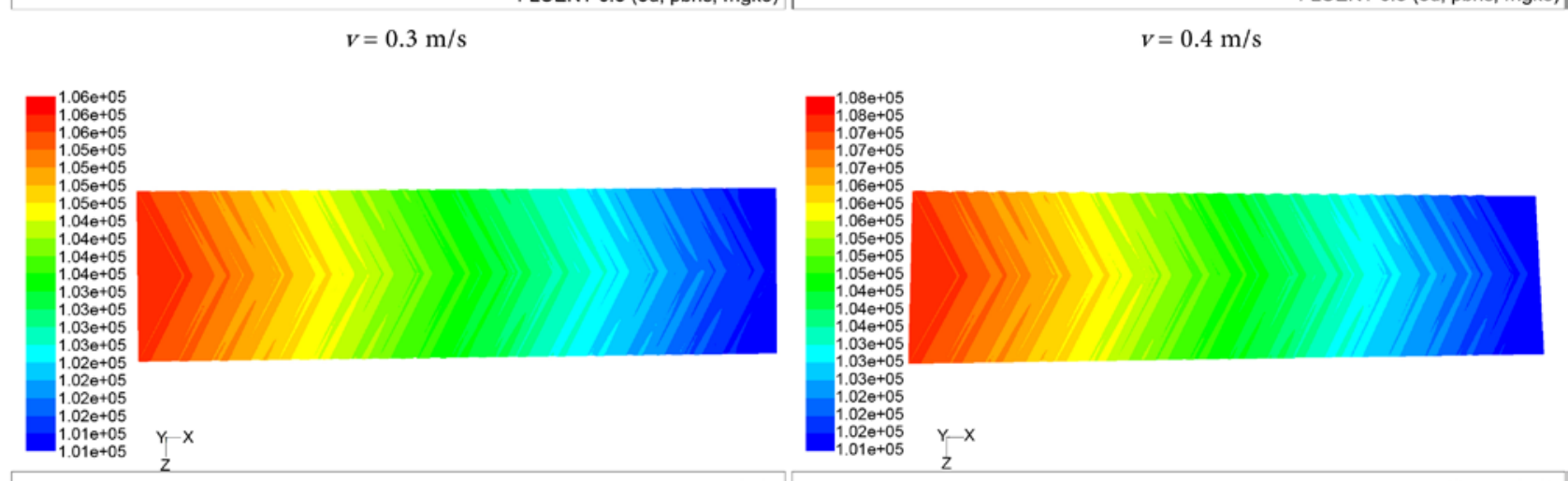

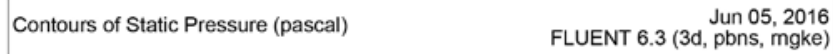
$V=0.5 \mathrm{~m} / \mathrm{s}$
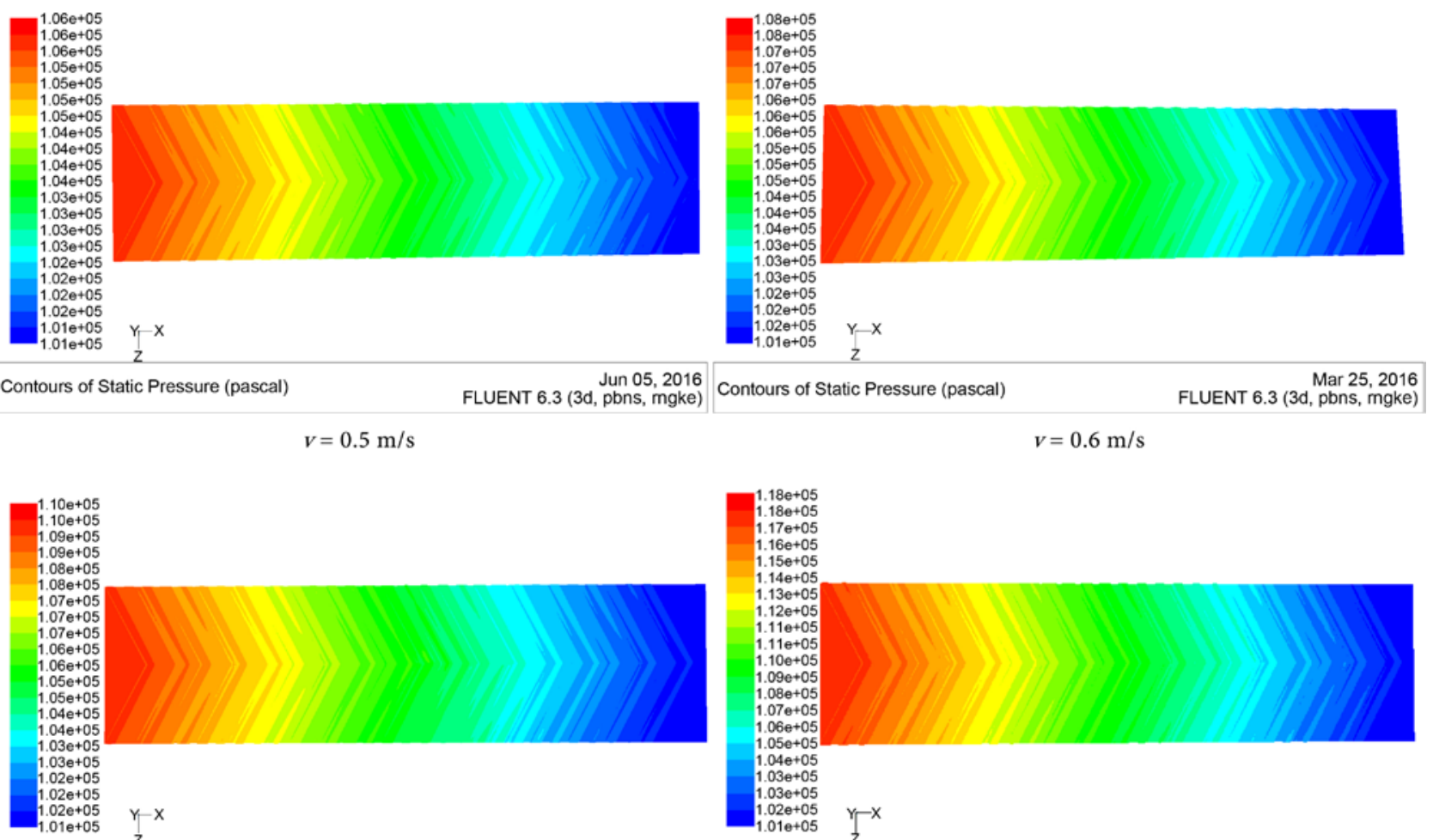

\begin{tabular}{lr}
\hline Contours of Static Pressure (pascal) & $\begin{array}{c}\text { Jun 05, } 2016 \\
\text { FLUENT } 6.3 \text { (3d, pbns, mgke) }\end{array}$ \\
$V=0.7 \mathrm{~m} / \mathrm{s}$ &
\end{tabular}
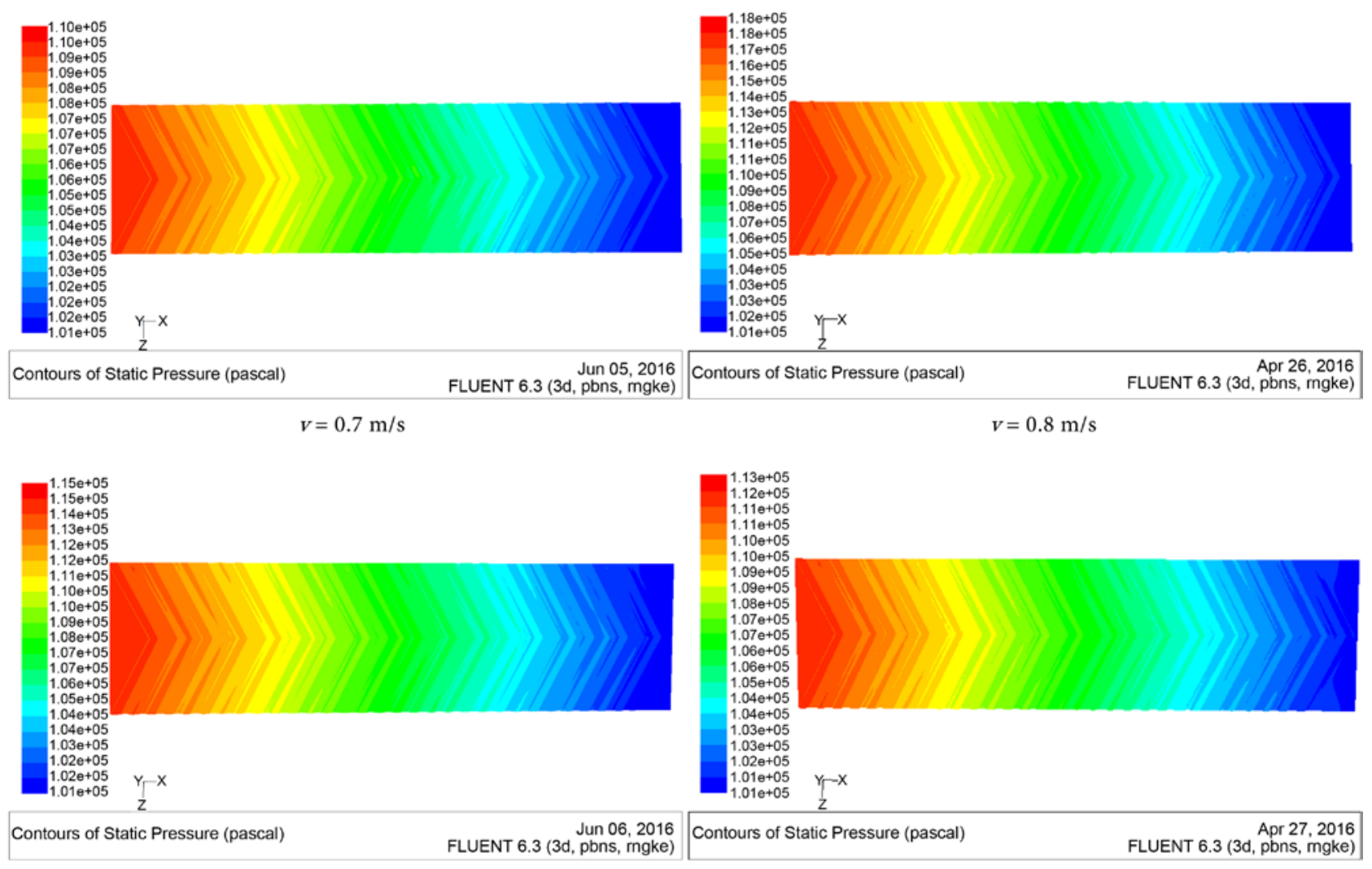

\begin{tabular}{|lr|}
\hline Contours of Static Pressure (pascal) & $\begin{array}{r}\text { Jun 06, } 2016 \\
\text { FLUENT } 6.3 \text { (3d, pbns, mgke) }\end{array}$ \\
$\qquad=0.9 \mathrm{~m} / \mathrm{s}$ &
\end{tabular}

Figure 16. Pressure distribution at different inlet velocity. 


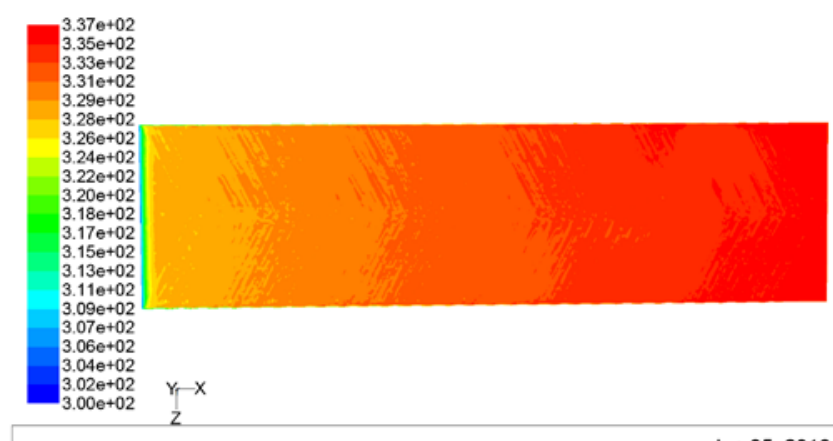

$\begin{array}{lr}\text { Contours of Static Temperature (k) } & \text { Jun 05, } 2016 \\ \text { FLUENT } 6.3 \text { (3d, pbns, mgke) }\end{array}$ $V=0.3 \mathrm{~m} / \mathrm{s}$

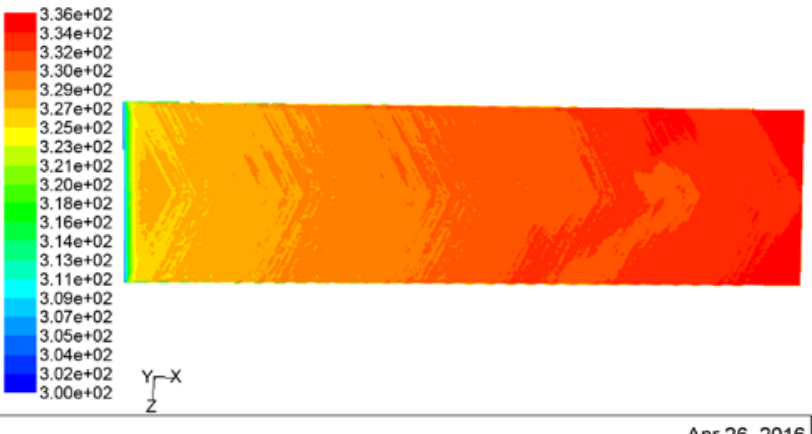

Contours of Static Temperature (k) FLUENT 6.3 (3d, pbris, mgke)

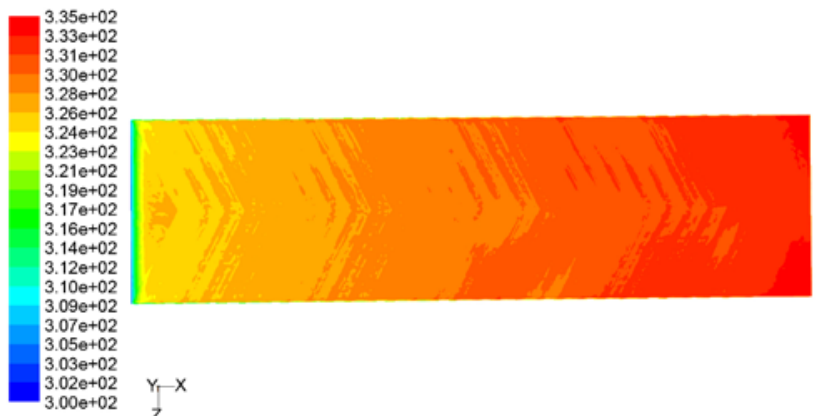

\begin{tabular}{|lr}
\hline Contours of Static Temperature (k) & $\begin{array}{r}\text { Jun 05, } 2016 \\
\text { FLUENT } 6.3 \text { (3d, pbns, mgke) }\end{array}$ \\
$V=0.5 \mathrm{~m} / \mathrm{s}$ &
\end{tabular}

Contours of Static Temperature (k)

$$
V=0.4 \mathrm{~m} / \mathrm{s}
$$

$3.35 \mathrm{e}+02$
$3.34 \mathrm{e}+02$
$3.32 \mathrm{e}+02$

$3.30 \mathrm{e}+02$
$3.28 \mathrm{e}+02$

$3.27 \mathrm{e}+02$
$3.25 \mathrm{e}+02$

3. $25 e+02$

$3.23 \mathrm{e}+02$
$3.21 \mathrm{e}+02$
$3.19 \mathrm{e}+02$

$3.19 \mathrm{e}+02$
$3.18 \mathrm{e}+02$

$3.18 \mathrm{e}+02$
$3.16 \mathrm{e}+02$

3. $14 \mathrm{e}+02$

3. $12 \mathrm{e}+02$

$3.11 e+02$

3.070

. $05 \mathrm{e}+02$

$3.04 \mathrm{e}+02$

$.02 \mathrm{e}+02 \quad Y-X$

$3.00 \mathrm{e}+02$

$3.30 \mathrm{e}+02$
$3.28 \mathrm{e}+02$

3. $26 \mathrm{e}+02$

$3.25 \mathrm{e}+02$
$3.23 \mathrm{e}+02$

$3.20 \mathrm{e}+02$

$3.20 \mathrm{e}+02$
$3.18 \mathrm{e}+02$

3. $17 \mathrm{e}+02$

$3.15 \mathrm{e}+02$
$3.13 \mathrm{e}+02$

3.12e+02

$3.08 \mathrm{e}+02$

$3.07 \mathrm{e}+02$

$3.05 \mathrm{e}+0$

$3.03 \mathrm{e}+02$
$3.02 \mathrm{e}+02 \quad \mathrm{Y}-\mathrm{X}$

$3.00 \mathrm{e}+02$

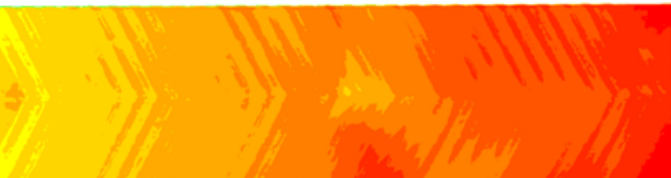

$Y X$

Contours of Static Temperature (k)

Contours of Static Temperature (k)

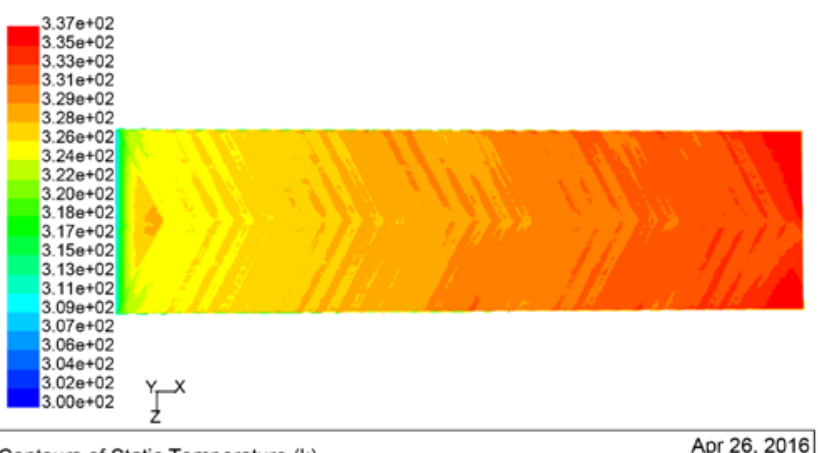

\section{$V=0.7 \mathrm{~m} / \mathrm{s}$}

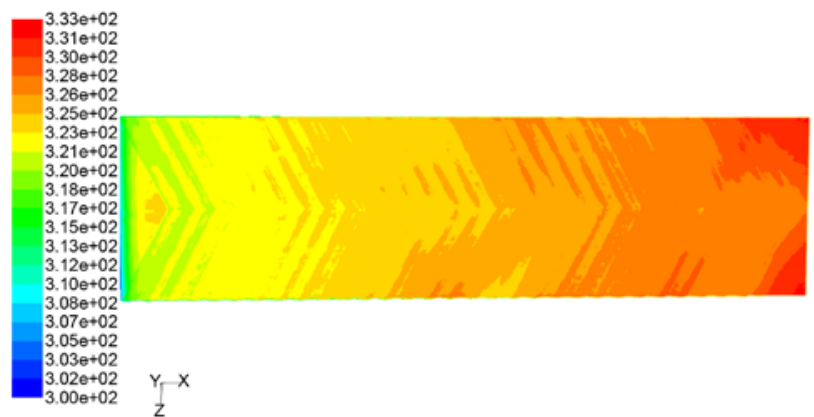

Contours of Static Temperature (k) FLUENT 6.3 (3d, pbns, mgke)

$V=0.9 \mathrm{~m} / \mathrm{s}$

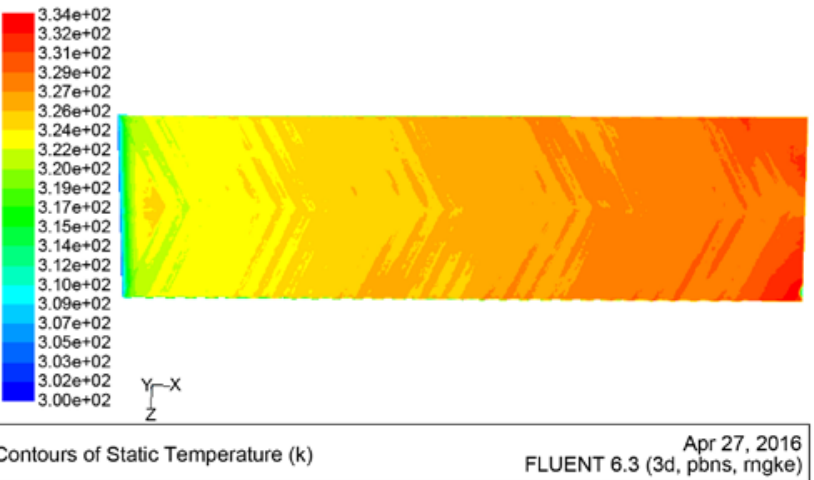

$V=0.8 \mathrm{~m} / \mathrm{s}$

$V=1 \mathrm{~m} / \mathrm{s}$

Figure 17. Temperature distribution at different inlet velocity. 

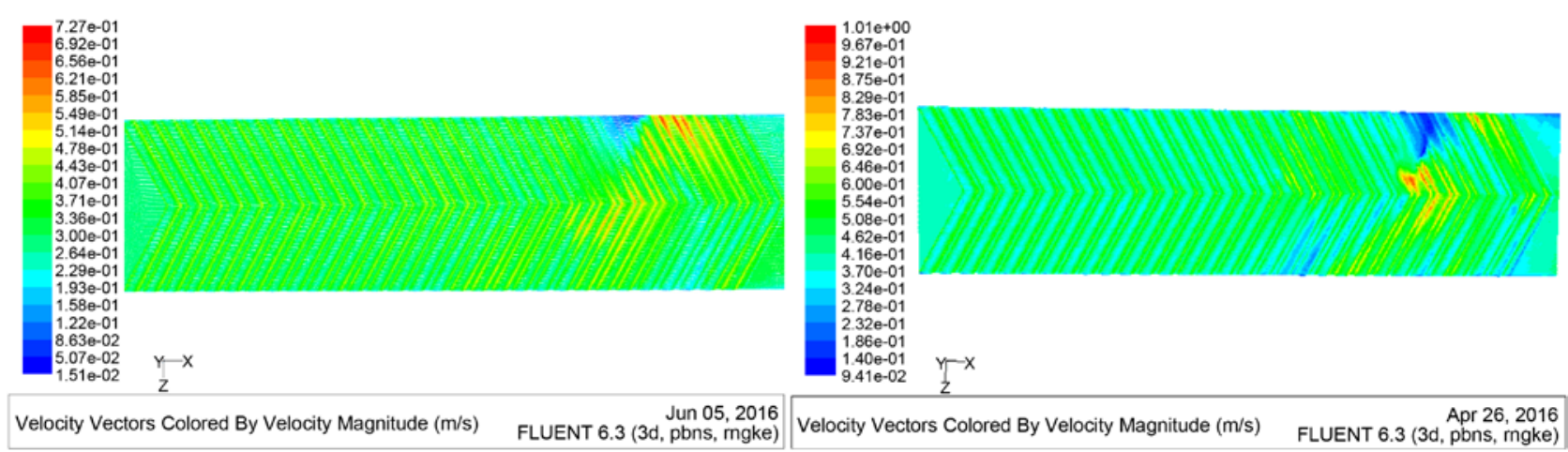

$$
V=0.3 \mathrm{~m} / \mathrm{s}
$$
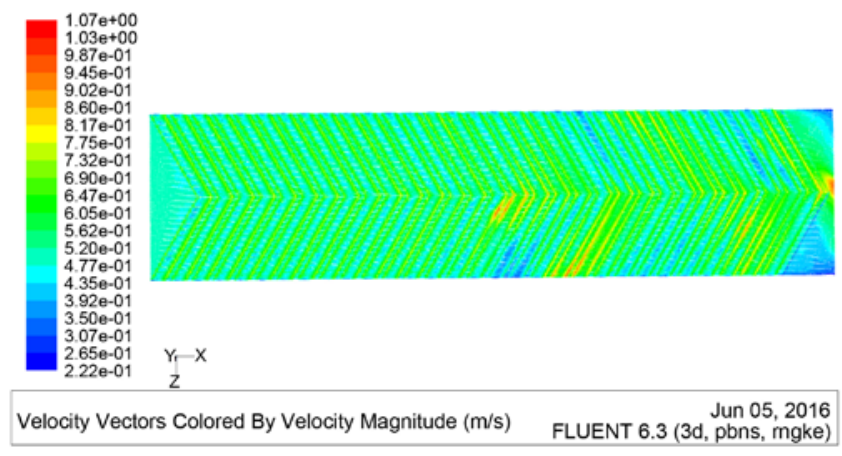

$$
V=0.5 \mathrm{~m} / \mathrm{s}
$$

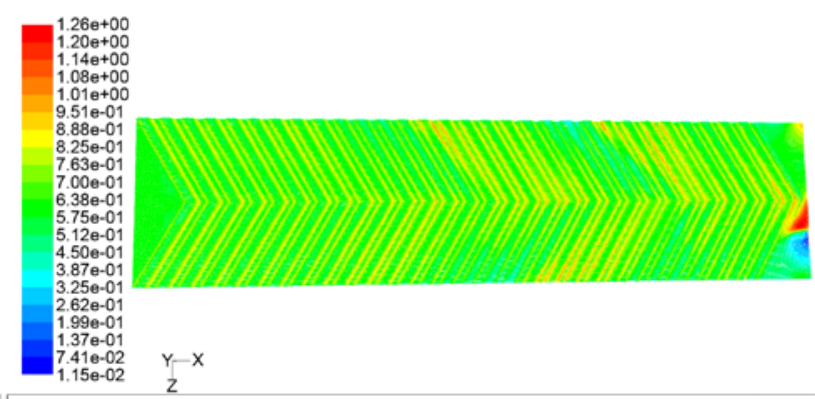

\begin{tabular}{|rr}
\hline Velocity Vectors Colored By Velocity Magnitude (m/s) & Mar 25, 2016 \\
\hline
\end{tabular}
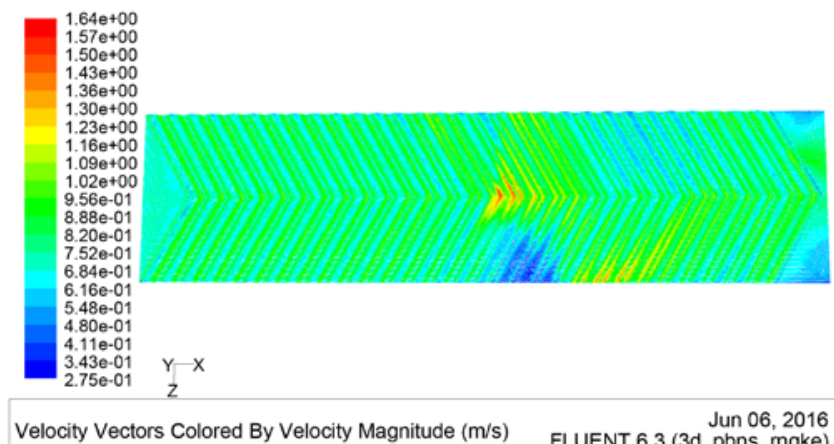

Velocity Vectors Colored By Velocity Magnitude $(\mathrm{m} / \mathrm{s})$ FLUENT 6.3 (3d, pbns, mgke)

$$
V=0.7 \mathrm{~m} / \mathrm{s}
$$
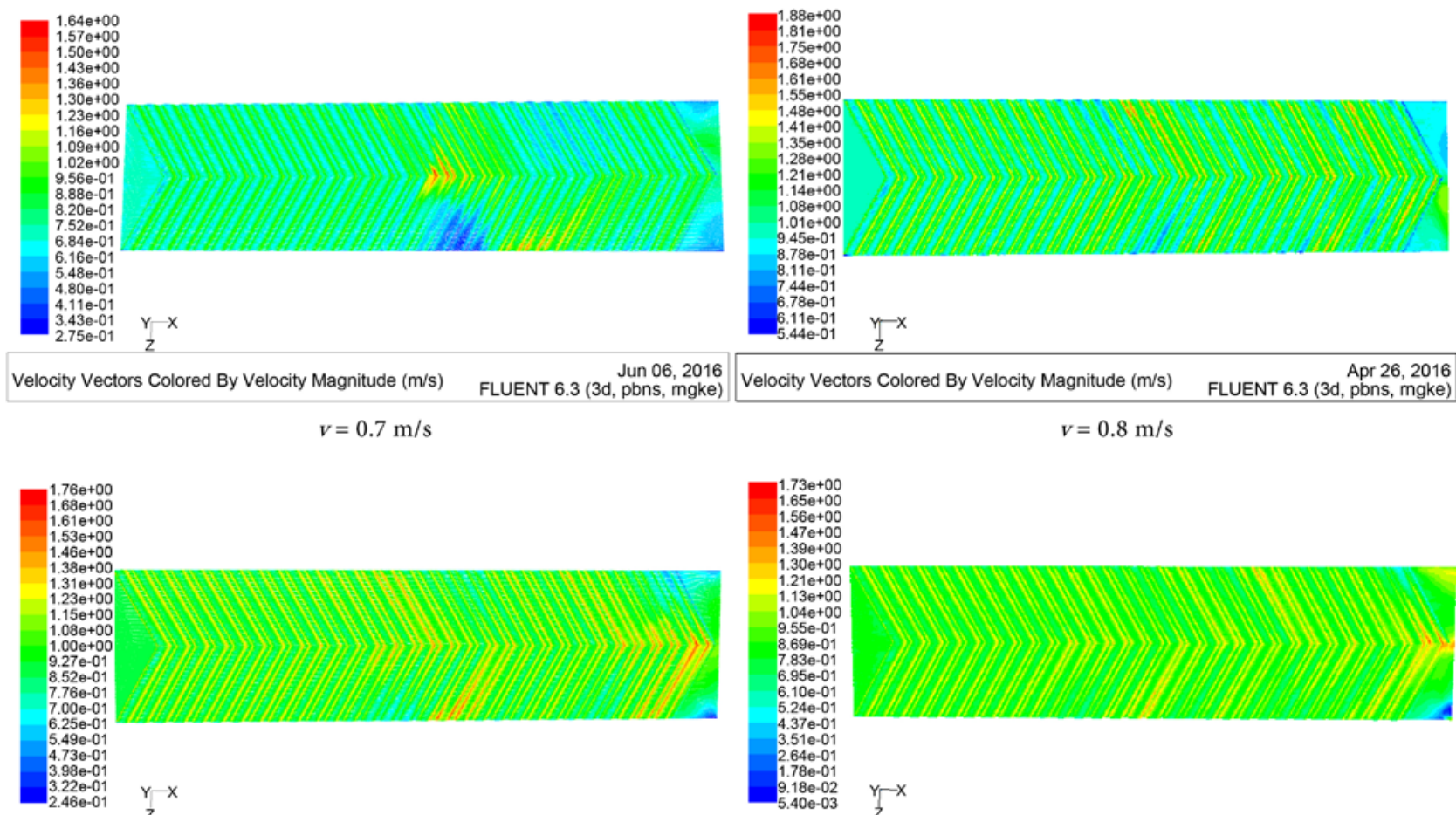

Velocity Vectors Colored By Velocity Magnitude $(\mathrm{m} / \mathrm{s})$ FLUENT 6.3 (3d, pbns, mgke)

$$
v=0.9 \mathrm{~m} / \mathrm{s}
$$$$
V=0.8 \mathrm{~m} / \mathrm{s}
$$

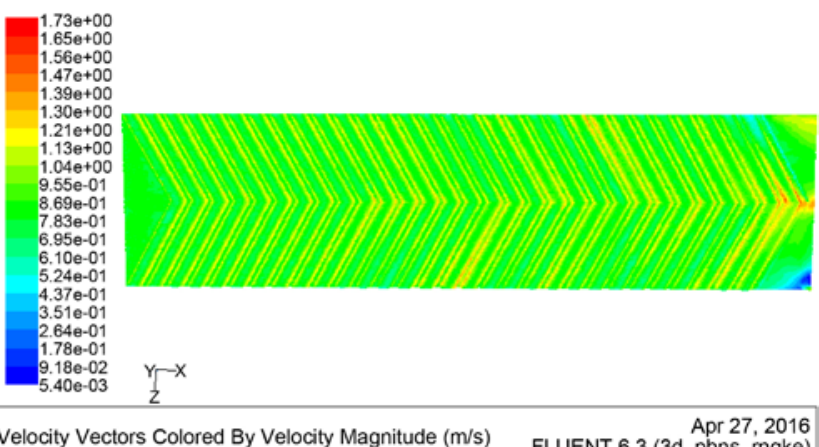

$\begin{array}{lr}\text { Velocity Vectors Colored By Velocity Magnitude (m/s) } & \text { Apr 27, } 2016 \\ \text { FLUENT 6.3 (3d, pbns, mgke) }\end{array}$ $V=1 \mathrm{~m} / \mathrm{s}$

Figure 18. Plate velocity distribution at different inlet velocity.

The local vector velocity at different inlet velocity is shown in Figure 19. 


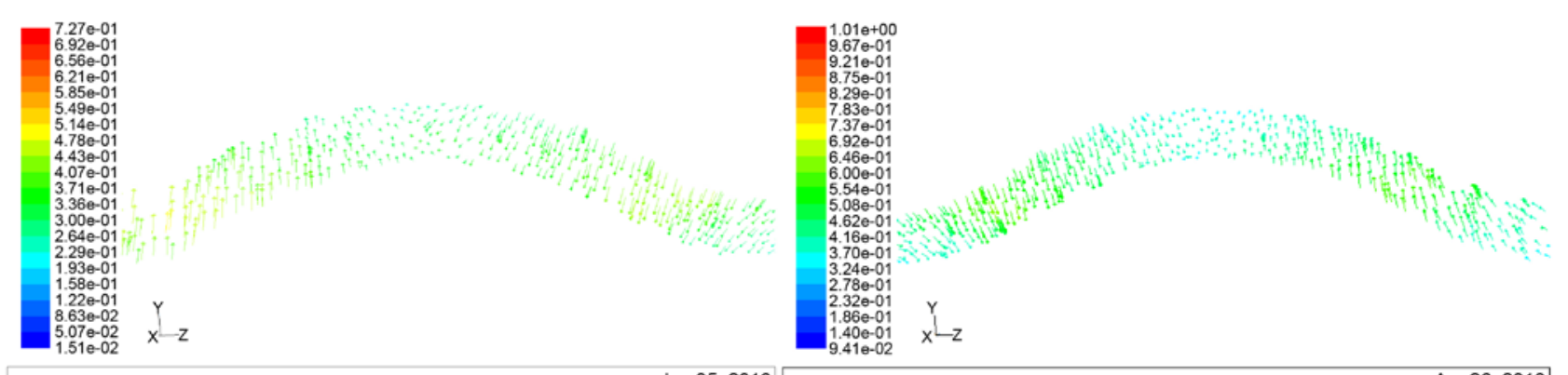

\begin{tabular}{|c|c|c|c|}
\hline Velocity Vectors Colored By Velocity Magnitude $(\mathrm{m} / \mathrm{s})$ & $\begin{array}{r}\text { Jun 05, } 2016 \\
\text { FLUENT } 6.3 \text { (3d, pbns, mgke) }\end{array}$ & Velocity Vectors Colored By Velocity Magnitude (m/s) & $\begin{array}{r}\text { Apr 26, } 2016 \\
\text { FLUENT } 6.3 \text { (3d, pbns, mgke) }\end{array}$ \\
\hline
\end{tabular}

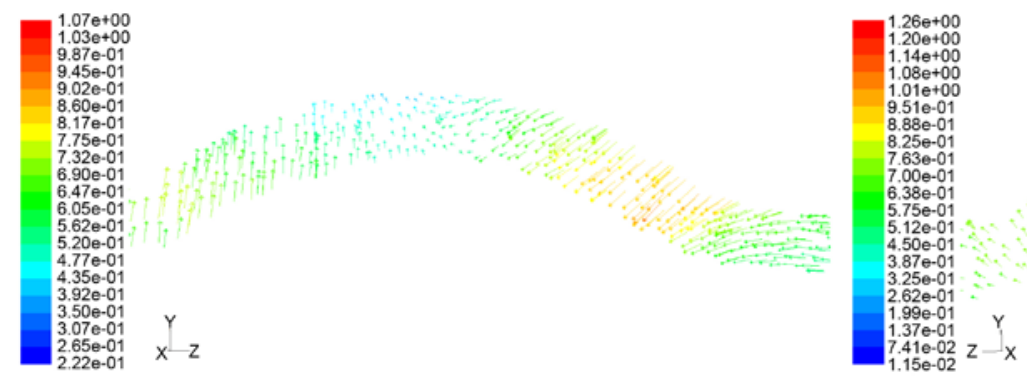

\begin{tabular}{|r|rr} 
Velocity Vectors Colored By Velocity Magnitude (m/s) & $\begin{array}{r}\text { Jun 05, } 2016 \\
\text { FLUENT } 6.3(3 \mathrm{~d}, \text { pbns, mgke) }\end{array}$ & $\begin{aligned} \text { Velocity Vectors Colored By Velocity Magnitude (m/s) } \\
\text { FLUENT 6.3 (3d, pbns, mgke) }\end{aligned}$ \\
$\qquad V=0.5 \mathrm{~m} / \mathrm{s}$ & $V=0.6 \mathrm{~m} / \mathrm{s}$
\end{tabular}
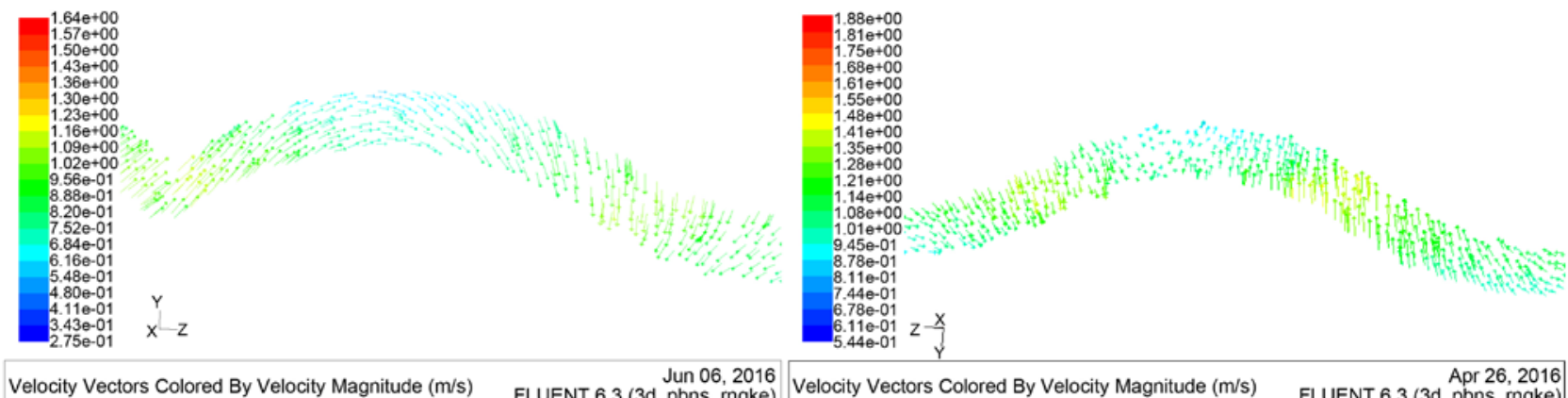

$\begin{array}{rrr}\text { Velocity Vectors Colored By Velocity Magnitude (m/s) } & \text { FLUENT 6.3 (3d, pbns, mgke) } & \begin{array}{r}\text { Jun 06, } 2016 \\ \text { Velocity Vectors Colored By Velocity Magnitude (m/s) }\end{array} \text { FLUENT 6.3 (3d, pbns, mgke) } \\ \qquad V=0.7 \mathrm{~m} / \mathrm{s} & V=0.8 \mathrm{~m} / \mathrm{s}\end{array}$
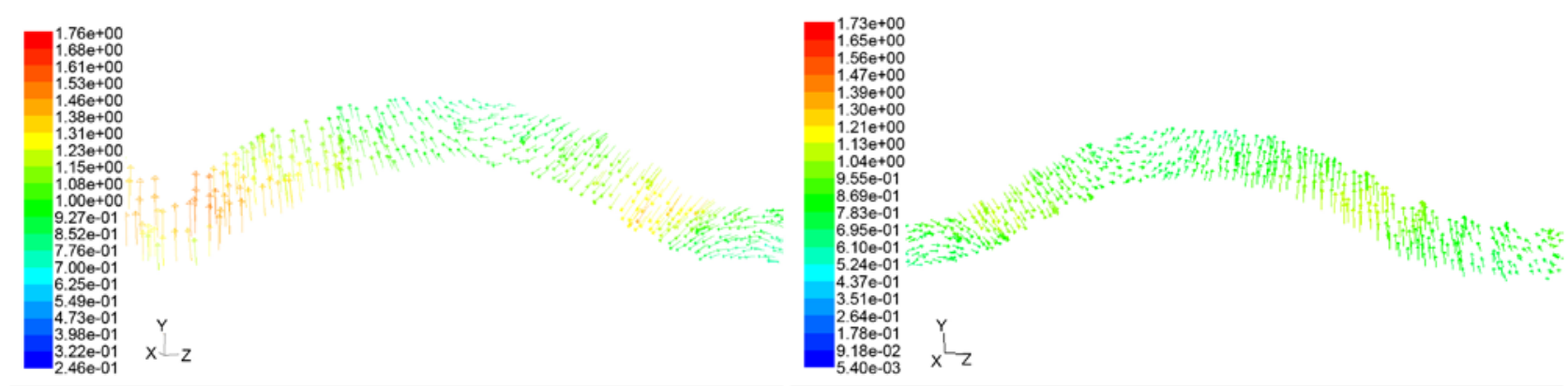

Velocity Vectors Colored By Velocity Magnitude (m/s) FLUENT 6.3 (3d, pbns, mgke)

Velocity Vectors Colored By Velocity Magnitude $(\mathrm{m} / \mathrm{s})$

FLUENT 6.3 (3d, Apr 27, 2016

$V=0.9 \mathrm{~m} / \mathrm{s}$

$V=1 \mathrm{~m} / \mathrm{s}$

Figure 19. Plate corrugation local vector velocity at different inlet velocity.

\subsection{Parametric Analysis}

The overall performance of the heat exchanger is determined by the heat transfer 
performance and hydraulic characteristics. Where $\mathrm{Nu}$ can be used to measure the heat transfer performance, $\Delta P$ can be used to measure the hydraulic characteristics. In this paper, the relationship between the heat transfer coefficient and the pressure drop is used to measure the overall performance of the heat exchanger, said $\eta$ :

$$
\eta=K / \Delta P^{1 / 3}
$$

Change the corrugation angle, the relationship of $\beta$ with $\Delta P, N u$, the average heat transfer coefficient and $\eta$ is shown as follow Figure 20.

With the increase of $\beta$, the flow of fluid is smoother at each inflection point between the plates, resulting in the decrease of heat transfer performance. $\mathrm{Nu}$ and average heat transfer coefficient decrease with the same trend, and the decrease is more obvious at $60^{\circ}$. The resistance through the plate is reduced, which causes the reduction of pressure drop, and it declines rapidly when the temperature is $60^{\circ}$. When the inclination is less than $60^{\circ}$, the cross section of the heat exchanger is crossed, and then the transition is a meandering flow, and the flow velocity decreases at the inflection point. The overall performance of the heat exchanger is increased first and then decreased, and the maximum value of which appears at $60^{\circ}$.

Change the corrugation spacing, the relationship of $\lambda$ with $\Delta P, N u$, the average heat transfer coefficient and $\eta$ is shown in Figure 21.

With the increase of $\lambda$, the Number of corrugations decreases, the contact of
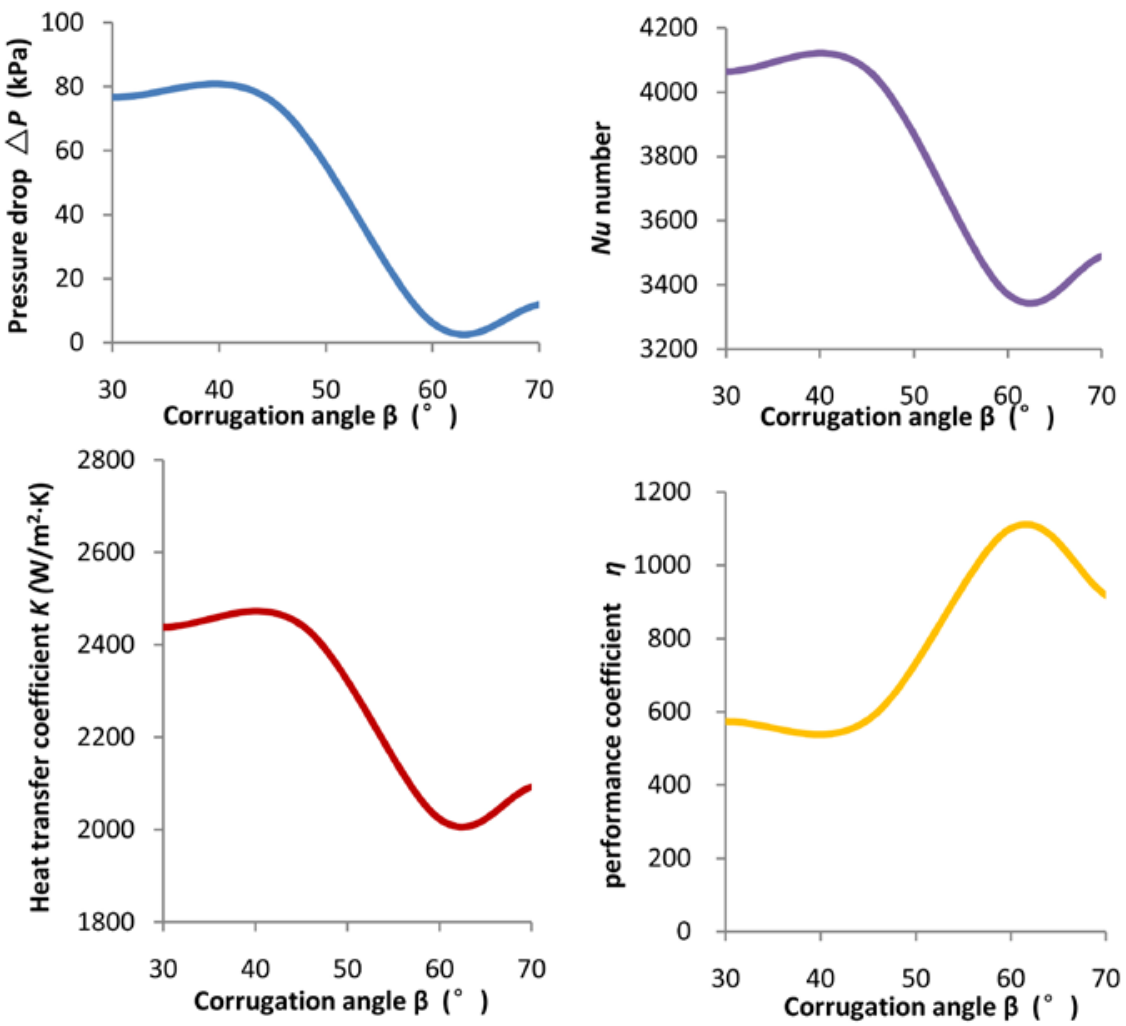

Figure 20. The relationship of $\beta$ with $\Delta P, N u$, average heat transfer coefficient and $\eta$. 

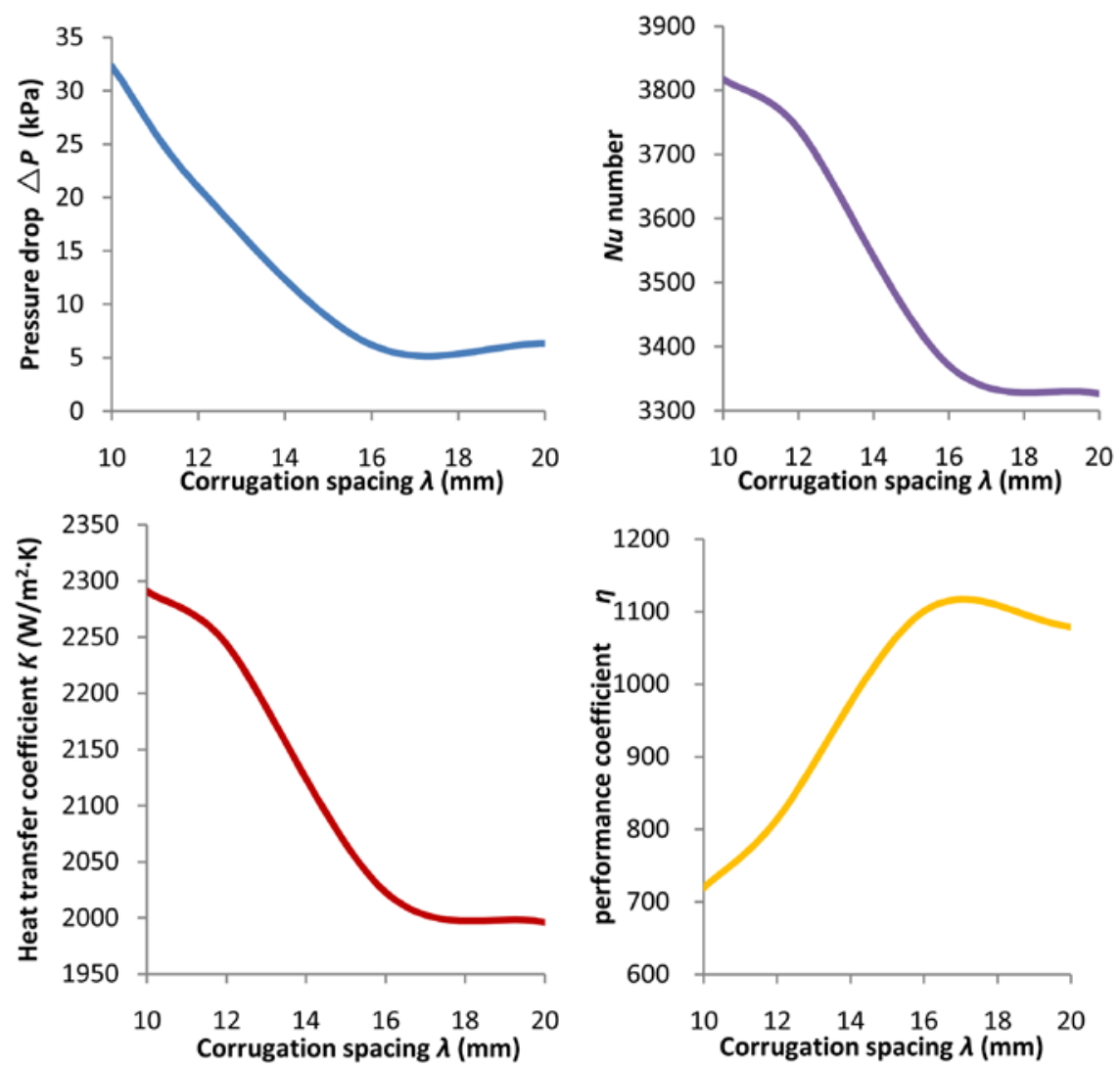

Figure 21. The relationship of $\lambda$ with $\Delta P, N u$, the average heat transfer coefficient and $\eta$.

the fluid between the plates decreases, the vortex region between the plates increases, the secondary flow caused by the contact decreases, resulting in reduced heat transfer performance, $\mathrm{Nu}$ Number and the average thermal coefficient decreases steadily with the same trend, and the pressure of the fluid flowing through the plate decreases, and the amplitude increases at $16 \mathrm{~mm}$, and then tends to be stable. The overall performance of the heat exchanger increased first and then became smooth, and the maximum value of which appears at $16 \mathrm{~mm}$.

Change corrugation depth, the relationship of $h$ with $\Delta P, N u$ Number, average heat transfer coefficient and $\eta$ is as follows Figure 22.

With the increase of $h$, the distance and time of the fluid flow between the plates increases, resulting in an increase in heat transfer performance. The $\mathrm{Nu}$ Number and the average heat transfer coefficient increase first and then decrease at the same trend, and reach the maximum value at $4 \mathrm{~mm}$, while the fluid need more flow resistance to flow through the plate, there is a larger increase when in the $5 \mathrm{~mm}$, and then it becomes stable. The velocity field of different $h$ is similar, and the flow dead zone is reduced. The overall performance of the heat exchanger first increases and then becomes stable, the maximum value of which appears at $4 \mathrm{~mm}$ Department.

Change the velocity of the fluid, the relationship of $v$ with $\Delta P, N u$ Number, average heat transfer coefficient and $\eta$ is as follows Figure 23. 

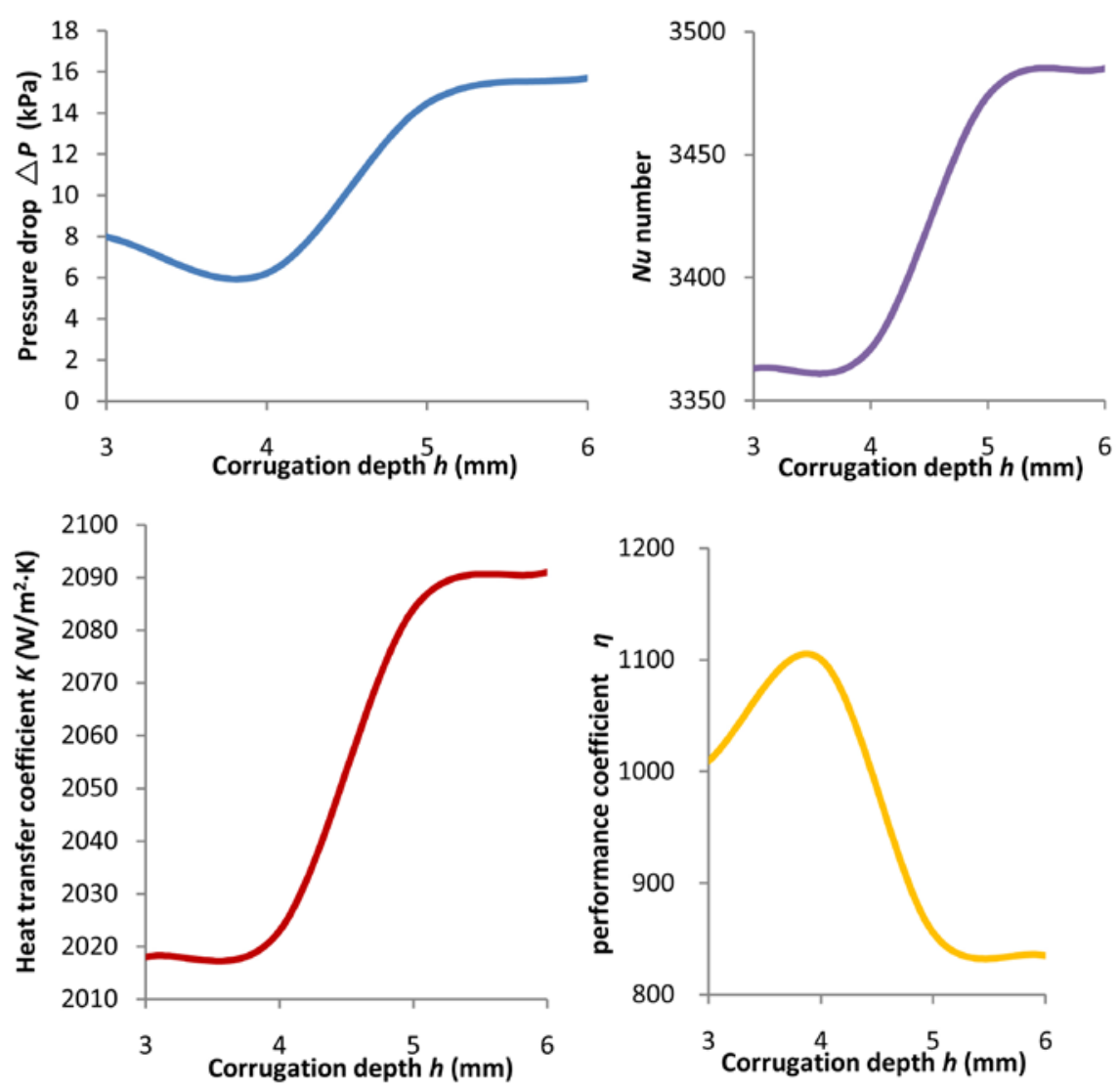

Figure 22. The relationship of $h$ with $\Delta P, N u$, the average heat transfer coefficient and $\eta$.

With the increase of velocity, the turbulence degree of the fluid in the plates increases, which leads to the enhancement of the heat transfer performance. The $\mathrm{Nu}$ Number and the average heat transfer coefficient increase with the same trend, and the fluid requires more flow resistance to flow through the plate. The overall performance of the heat exchanger fluctuates little and has little effect.

\section{Conclusion}

In this paper, CFD method is used to predict the performance of plate heat exchanger in solar heating system. The influence of structural parameters like ripple inclination, ripple depth, ripple spacing and fluid velocity on the temperature field, pressure field and velocity field of the heat exchanger were studied by using FLUENT6.3 software, further analyzing its influence on the heat transfer and resistance of the chevron plate heat exchanger. The results show that the heat transfer effect at the contact point of corrugated plate heat exchanger is the best, the turbulence is the highest, the heat transfer is strengthened, but the pressure loss after passing the contact point of the fluid reaches the maximum, which leads to the increase of the pressure drop. With the increase of corrugation angle, there are two different flow patterns appear between the plates, and the overall performance first increases and then decreases, and it is optimal at $60^{\circ}$. With the increase of ripple spacing, the heat transfer coefficient 

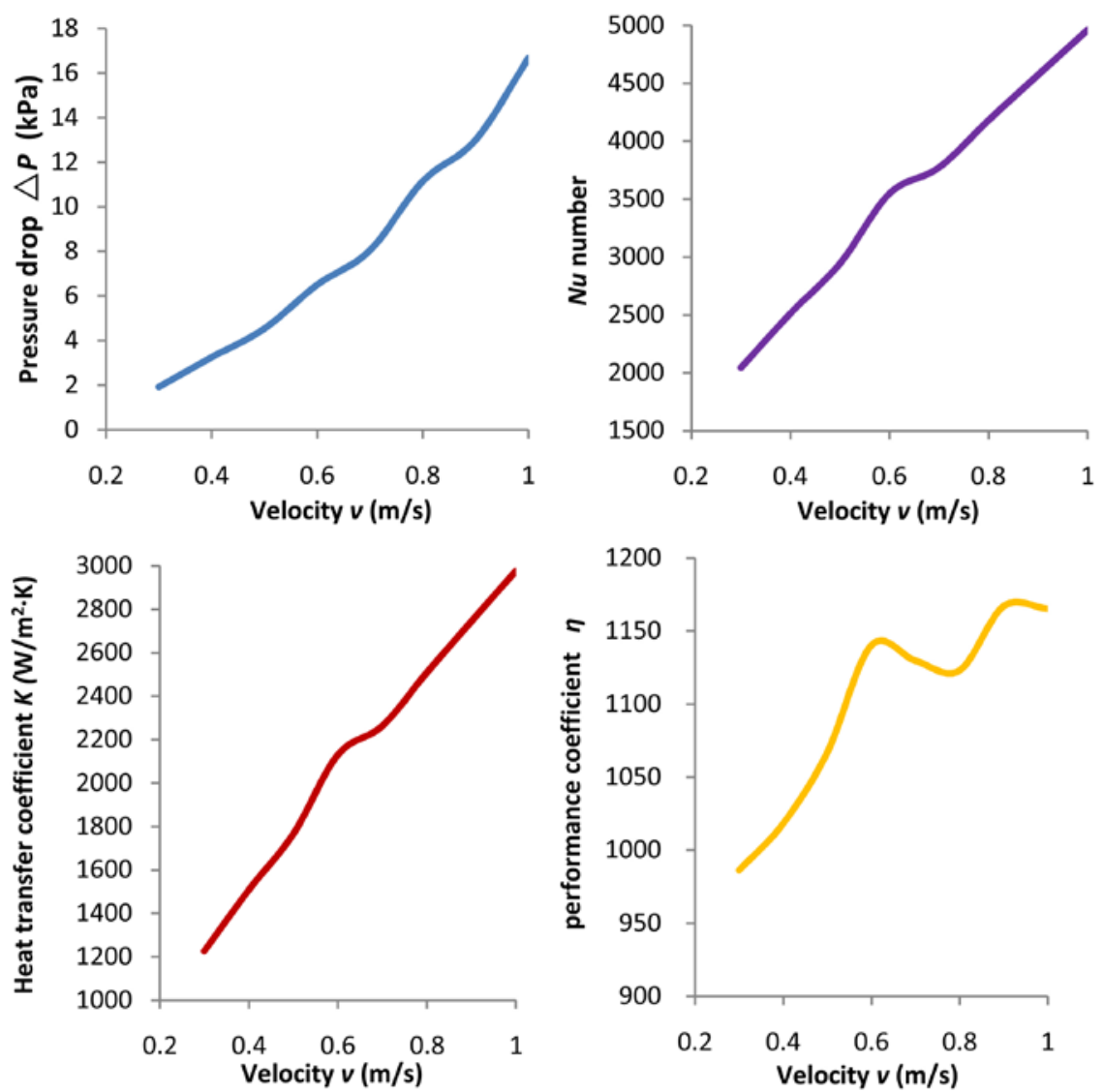

Figure 23. The relationship of velocity with $\Delta P, N u$, the average heat transfer coefficient and $\eta$.

and pressure drop are reduced at the same time, but the amplitude is different, and the overall performance reaches the maximum at $16 \mathrm{~mm}$. The increase of the ripple depth leads to heat transfer coefficient increasing first and decreasing then, and the decrease of the pressure drop, and the overall performance is the best at $4 \mathrm{~mm}$. The increase of the fluid flow rate leads to the increase of the heat transfer coefficient and the pressure drop, and the overall performance is gradually increased. In this paper, the optimal structure of the plate heat exchanger is ripple angle of $60^{\circ}$, ripple depth of $4 \mathrm{~mm}$, ripple spacing of $16 \mathrm{~mm}$. The results of the above analysis are in good agreement with the conclusion of the references, indicating that the model used in this simulation can well reflect the flow and heat transfer characteristics of the chevron plate heat exchanger.

\section{Acknowledgements}

The author would like to acknowledge the following projects for financial support. Wind and solar energy utilization technology of Inner Mongolia University of Technology key laboratory open fund project authorized by China's ministry of education: Wind Speed Prediction Research Based on Geographic Information System. The National Natural Science Foundation of China: Performance Analysis of Functioned Brackish Water for Lighting-Induced Evaporation Type 
Solar Desalination System. And Science \& technology plan projects in Inner Mongolia (ZD2012MS0703).

\section{References}

[1] Wang, L., Sundén, B. and Manglik, R.M. (2007) Plate Heat Exchangers: Design, Applications and Performance. Mechanical Engineering, 5, 58.

[2] Focke, W.W., Zachariades, J. and Olivier, I. (1985) The Effect of the Corrugation Inclination Angle on the Thermohydraulic Performance of Plate Heat Exchangers. International Journal of Heat \& Mass Transfer, 28, 1469-1479.

[3] Muley, A. and Manglik, R.M. (1999) Experimental Study of Turbulent Flow Heat Transfer and Pressure Drop in a Plate Heat Exchanger with Chevron Plates. Journal of Heat Transfer, 121, 110-117. https://doi.org/10.1115/1.2825923

[4] Tsai, Y.C., Liu, F.B. and Shen, P.T. (2009) Investigations of the Pressure Drop and Flow Distribution in a Chevron-Type Plate Heat Exchanger. International Communications in Heat \& Mass Transfer, 36, 574-578.

[5] Khan, T.S., Khan, M.S., Chyu, M.C. and Ayub, Z.H. (2010) Experimental Investigation of Single Phase Convective Heat Transfer Coefficient in a Corrugated Plate Heat Exchanger for Multiple Plate Configurations. Applied Thermal Engineering, 30, 1058-1065.

[6] Gherasim, I., Taws, M., Galanis, N. and Cong, T.N. (2011) Heat Transfer and Fluid Flow in a Plate Heat Exchanger Part I. Experimental Investigation. International Journal of Thermal Sciences, 50, 1492-1498.

[7] Martin, H. (1996) A Theoretical Approach to Predict the Performance of Chevron-Type Plate Heat Exchangers. Chemical Engineering \& Processing Process Intensification, 35, 301-310.

[8] Dović, D., Palm, B. and Švaić, S. (2009) Generalized Correlations for Predicting Heat Transfer and Pressure Drop in Plate Heat Exchanger Channels of Arbitrary Geometry. International Journal of Heat \& Mass Transfer, 52, 4553-4554.

[9] Kays, W.M. and London, A.L. (1984) Compact Heat Exchangers. 3rd Edition, McGraw-Hill Book Company.

[10] Hesselgreaves, J.E. (2001) Compact Heat Exchangers: Selection, Design and Operation. Pergamon Pr.

[11] Selvam, M.A.J., Senthil, K.P. and Muthuraman, S. (2012) The Characteristics of Brazed Plate Heat Exchangers with Different Chevron Angles. Heat Exchangers Basics Design Applications. InTech.

[12] Bobbili, P.R. and Sunden, B. (2009) Pressure Drop in Multi-Parallel Channels of Corrugated Plate Steam Condensers. Heat Transfer Engineering, 30, 1024-1032. https://doi.org/10.1080/01457630902921048

[13] Fernandes, C.S., Dias, R., Nobrega, J.M., Afonso, I.M., Melo, L.F. and Maia, J.M. (2005) Simulation of Stirred Yoghurt Processing in Plate Heat Exchangers. Journal of Food Engineering, 69, 281-290.

[14] Kanaris, A.G., Mouza, A.A. and Paras, S.V. (2006) Flow and Heat Transfer Prediction in a Corrugated Plate Heat Exchanger using Cfd Code. Chemical Engineering \& Technology, 29, 923-930. https://doi.org/10.1002/ceat.200600093

[15] Stogiannisa, I.A., Paras, S.V., Arsenyevab, O.P. and Kapustenkob, P.O. (2013) Cfd Modelling of Hydrodynamics and Heat Transfer in Channels of a Phe.

[16] Sundén, B. (2014) Cfd Simulation of Heat Transfer and Pressure Drop in Compact 
Brazed Plate Heat Exchangers, Heat Transfer Engineering, 35, 358-366. https://doi.org/10.1080/01457632.2013.828557

[17] Sarraf, K., Launay, S. and Tadrist, L. (2015) Complex 3d-Flow Analysis and Corrugation Angle Effect in Plate Heat Exchangers. International Journal of Thermal Sciences, 94, 126-138.

Submit or recommend next manuscript to SCIRP and we will provide best service for you:

Accepting pre-submission inquiries through Email, Facebook, LinkedIn, Twitter, etc. A wide selection of journals (inclusive of 9 subjects, more than 200 journals) Providing 24-hour high-quality service User-friendly online submission system Fair and swift peer-review system Efficient typesetting and proofreading procedure Display of the result of downloads and visits, as well as the number of cited articles Maximum dissemination of your research work

Submit your manuscript at: http://papersubmission.scirp.org/ Or contact ojfd@scirp.org 